\title{
Antifungal Pharmacokinetics and Pharmacodynamics
}

\author{
Alexander J. Lepak and David R. Andes \\ University of Wisconsin, Madison, Wisconsin 53705 \\ Correspondence: dra@medicine.wisc.edu
}

\begin{abstract}
Successful treatment of infectious diseases requires choice of the most suitable antimicrobial agent, comprising consideration of drug pharmacokinetics (PK), including penetration into infection site, pathogen susceptibility, optimal route of drug administration, drug dose, frequency of administration, duration of therapy, and drug toxicity. Antimicrobial pharmacokinetic/pharmacodynamic (PK/PD) studies consider these variables and have been useful in drug development, optimizing dosing regimens, determining susceptibility breakpoints, and limiting toxicity of antifungal therapy. Here the concepts of antifungal PK/PD studies are reviewed, with emphasis on methodology and application. The initial sections of this review focus on principles and methodology. Then the pharmacodynamics of each major antifungal drug class (polyenes, flucytosine, azoles, and echinocandins) is discussed. Finally, the review discusses novel areas of pharmacodynamic investigation in the study and application of combination therapy.
\end{abstract}

\section{PHARMACOKINETICS}

Pharmacokinetic (PK) studies describe the host exposure and elimination of a drug. Common PK measures include absorption, accumulation in various tissues or compartments, metabolism, and elimination. From a pharmacodynamic (PD) perspective, PK measures represent drug exposure with respect to the host, for example, translating a dose (i.e., $\mathrm{mg} / \mathrm{kg}$ ) to a drug exposure (e.g., area under the concentration curve, or AUC) (Drusano 2004). Traditional PK measures considered in PD analyses include the maximal concentration $\left(C_{\max }\right)$, the total exposure or AUC, and assessment of concentration over time by use of the elimination half-life. The most common site of PK assessment is the serum. However, other PK tissue sites of suggested clinical relevance include the cerebrospinal fluid, ocular compartments, the urine, and the epithelial lining fluid (ELF) compartment of the lung. Most fungal infections occur in the extracellular fluid compartment, and, therefore, serum or plasma drug concentrations correlate quite well with drug concentrations at the site of infection (Mukherjee et al. 2006). This has been shown to be true for candidiasis, including mucocutaneous and invasive/disseminated disease (Andes 2004; Mukherjee et al. 2006). However, a subset of fungal infections involves primarily pulmonary parenchymal disease, for example, aspergillosis and zygomy-

Editors: Arturo Casadevall, Aaron P. Mitchell, Judith Berman, Kyung J. Kwon-Chung, John R. Perfect, and Joseph Heitman

Additional Perspectives on Human Fungal Pathogens available at www.perspectivesinmedicine.org

Copyright (C) 2015 Cold Spring Harbor Laboratory Press; all rights reserved; doi: 10.1101/cshperspect.a019653

Cite this article as Cold Spring Harb Perspect Med 2015;5:a019653 
cetes. The relevance of drug concentration within the ELF of the lung has been investigated, but the evidence that ELF concentrations are more predictive of serum or plasma concentrations is lacking. This is likely because of the fact that these disease syndromes are invasive in nature, with significant tissue involvement. However, ELF concentrations may be more relevant for prophylaxis as the organism must first colonize and infect the alveolar space, and prophylaxis studies in animal models using ELF concentrations are an emerging area of study (Rodvold et al. 2011). Infection of the central nervous system (CNS), eye, and lower urinary tract are examples in which drug penetration and PK measurement at the site of infection has been shown to be relevant (Perfect et al. 1986; Savani et al. 1987; Groll et al. 2000; Gauthier et al. 2005). For example, only flucytosine and fluconazole achieve reliably therapeutic urine concentrations for treatment of lower urinary tract infections (Fisher et al. 2011). For intraocular and CNS infections fluconazole, voriconazole, flucytosine, and liposomal amphotericin B would be optimal from the PK standpoint (Utz 1975; Brammer et al. 1990; Purkins et al. 2002; Sun et al. 2009; Riddell et al. 2011; Schwartz et al. 2011).

An additional PK measurement that warrants consideration is binding of drug to serum albumin (Kunin et al. 1973; Craig and Kunin 1976; Craig and Ebert 1989). A relatively large number of antimicrobial treatment studies have shown that only free, non-protein-bound drug is pharmacologically active (Craig and Welling 1977; Zeitlinger et al. 2011). This can be a result of limited penetration of protein-bound drug to the site of infection as well as limited ability of protein-bound drug to bind at the site of activity. In the context of antifungal drugs, the relevance of protein binding has been shown for both triazoles and echinocandins and will be elucidated in the following sections (Andes 2003a; Andes et al. 2010).

\section{In Vitro Drug Potency}

A unique factor in antimicrobial PD studies is ability to consider $\mathrm{PK}$ relative to a measure of drug potency, specifically the in vitro susceptibility test most commonly expressed as the minimum inhibitory concentration (MIC). A variety of antifungal susceptibility testing protocols have been standardized using broth microdilution, disk-diffusion, and antifungal gradient strip (Etest) methodologies (Wanger et al. 1995; CLSI 2004, 2008a,b,c; EUCAST 2008, 2012). In each, the goal is to define the minimum concentration of drug that inhibits some degree of organism growth MIC. MIC end points and time at which they are read can differ from drug to drug and between standardized methodologies (Chryssanthou and Cuenca-Estrella 2006; Pfaller and Diekema 2012).

\section{In Vitro PK/PD Models}

In vitro $\mathrm{PK} / \mathrm{PD}$ studies are often the first to define the PD characteristics. The majority of in vitro $\mathrm{PK} / \mathrm{PD}$ studies use a nutrient broth system of variable complexity ranging from a single static environment to multiple chambers to allow the investigator to closely mimic human PK profiles. The advantages of in vitro systems include the ability to frequently assess microbiologic effect and closely parallel PK in patients. The disadvantages of in vitro approaches include the lack of the clinical infection site, which does not account for the host immune system and tissue $\mathrm{PK}$, including protein binding. Additionally, in vitro models do not always account for variability in organism fitness that is often observed in vivo. However, the models provide an opportunity to accurately assess PD characteristics, such as the impact of concentration and can also be useful for estimating the PK/ PD target (Lewis et al. 1998, 2000; Ernst et al. 1999; Te Dorsthorst et al. 2013). More recently, investigators have modified in vitro systems to more closely mimic the host and infection site. For example, a human cell culture with a bilayer of alveolar epithelial cells and pulmonary artery endothelial cells has been shown to be particularly useful to examine the pharmacology of invasive pulmonary aspergillosis treatment (Hope et al. 2007a; Gregson et al. 2012; Jeans et al. 2012a,b). This model has also been valuable in examining novel methods of drug delivery via 
nebulized or airway route (Al-Nakeeb et al. 2012).

\section{Animal PK/PD Models}

Most antifungal animal model studies are performed in mice; however, rats, rabbits, and other mammals have been used. The mice are often immunosuppressed as a result of cyclophosphamide treatment, which renders them neutropenic. Additional immune suppression with high-dose corticosteroids is used, for example, in pulmonary fungal infection models to reduce activity of alveolar macrophages. The purpose of the immune suppression is to ensure that reproducible infection is obtained in the minimal number of animals necessary for each treatment group. An additional factor of importance in animal model design is the infection itself, which should mimic as closely as possible what is observed clinically in patients. For example, invasive candidiasis animal models often involve infecting the animals by intravenous inoculation, which mimics disseminated disease in patients. Conversely, most invasive aspergillosis models use inhalational infection to mimic pulmonary disease.

Another critical component of an animal model PK/PD study includes the ability to reproducibly measure and quantify outcome. The most common measures of outcome include assessment of organism burden or animal survival. The former typically provides a larger range of effect to discern effective versus ineffective therapy and almost always requires use of a small number of animals. Assessment of mortality is complicated by nonpathogen causes of mortality in immunocompromised animal models and more recent changes in animal care regulations that introduce variability in determination of the animal distress level appropriate for euthanasia. Organism burden assessment is relatively straightforward for yeast pathogens because target organs can be homogenized and serial dilutions plated onto media to determine fungal burden by colony-forming unit (cfu) counts. This, however, is more problematic for filamentous fungi. These organisms, when grown from tissue homogenates, do not reproducibly produce a 1:1 ratio of colony to fungal cell, as filamentous fungi grow as long, interconnected filaments of multiple cells. Therefore, a colony on a plate may represent a small fungal filament of only a few cells or may arise from a large mass of cells. Additionally, discrete colonies on a plate quickly coalesce into a large expanding fungal mass, making counting individual colonies difficult. There have been a number of nonculture approaches developed to assess organism burden in tissue for filamentous fungi. Examples include measurement of fungal cell wall component (galactomannan and $\beta$-glucan), pulmonary imaging, histopathology, and lung weight (Petraitis et al. 1998, 2002, 2003, 2006, 2009; Petraitiene et al. 2001, 2002; Francesconi et al. 2006; Meletiadis et al. 2006; Sheppard et al. 2006; Brock et al. 2008; Vallor et al. 2008; Wiederhold et al. 2008; Walsh et al. 2009; Howard et al. 2011; Lengerova et al. 2012; Galiger et al. 2013). Additionally, quantitative real-time polymerase chain reaction can be used to account for each organism. This nucleic acid assay provides a large dynamic range and has been shown to correlate well with mortality in animal models (Bowman et al. 2001; Francesconi et al. 2006; Sheppard et al. 2006; Vallor et al. 2008; Lengerova et al. 2012; Lepak et al. 2013a,b,c).

Experimental Determination of the PK/PD Measure and Magnitude Linked to Efficacy

PD studies integrate drug PKs, including drug concentration over time, in vitro potency (MIC), and treatment efficacy (Craig 1998; Mukherjee et al. 2006; Drusano 2007). There are two major $\mathrm{PK} / \mathrm{PD}$ questions that are critical for optimizing therapy. First, which PK/PD measure (index) is most closely linked to efficacy? Traditionally, three PD indices have been used to describe the relationship among PK, MIC, and drug effect. These include peak drug concentrations in relation to the $\mathrm{MIC}\left(C_{\max } / \mathrm{MIC}\right)$, the area under the drug concentration curve in relation to MIC (AUC/MIC), and the time (expressed as a percentage of the dosing interval) that drug concentrations are expected to exceed the MIC (\%T> MIC) (Fig. 1). The PD index 
A.J. Lepak and D.R. Andes

that correlates best (i.e., predicts) with efficacy is largely dependent on the impact of drug concentration on organism survival over time. There are two patterns of activity, concentration dependent or concentration independent (also known as time dependent). Following exposure to concentration-dependent drugs, both the rate and extent of organism killing increase as the drug concentration is escalated. The PD indices associated with concentration-dependent action are $C_{\max } / \mathrm{MIC}$ and AUC/MIC. The dosing strategy associated with maximal efficacy in this situation is administration of large doses infrequently to take advantage of the concentrationdependent action. Concentration-independent agents are characterized by a threshold of maximal activity that occurs at drug concentrations close to the MIC. The PD index most commonly associated with time-dependent action is $\% T>$ MIC. The dosing strategy associated with maximal efficacy in this situation is administration of lower doses more frequently to increase the duration of exposure at levels just above the MIC.

A second exposure-response factor, the postantifungal effect (PAFE), can also influence PD relationships. The PAFE is the drug effect following drug exposures above the MIC (Vogelman et al. 1988). For some drug classes there is a period of prolonged growth suppression following drug exposure, whereas for others there is rapid growth recovery. Extended PAFE periods allow dosing intervals to be lengthened. For time-dependent killing organisms the PAFE reduces reliance on concentrations above the MIC $(\% T>\mathrm{MIC})$ and increases relevance of the total drug exposure or AUC/MIC index. This phenomenon was first observed and well described in bacteria (Eagle and Musselman 1949; Vogelman and Craig 1985; Craig and Vogelman 1987; Vogelman et al. 1988; Craig 1998) but has also been described in antifungal therapy (Fig. 2) (Turnidge et al. 1994; Andes 2003b, 2004; Mukherjee et al. 2006). For example, triazoles exhibit prolonged PAFEs, and it has been shown that AUC/MIC is the optimal predictive index (Turnidge et al. 1994; Andes and van Ogtrop 1999; Ernst et al. 2000; Andes et al. 2003a,b, 2004), whereas flucytosine exhibits little PAFE, and in this case $\% T>$ MIC is the most predictive PD index (Andes and van Ogtrop 2000). Finally, as elucidated previously, $C_{\max } / \mathrm{MIC}$ is the predictive PD index for concentration-dependent drugs; however, whether there is evidence of prolonged PAFE, AUC/MIC and $C_{\max } / \mathrm{MIC}$ can both be predictive of efficacy. This is particularly true for echinocandins, which exhibit concentration-dependent activity but also have a prolonged PAFE (Walsh et al. 1991; Ernst et al. 2000, 2002a; Andes et al. 2003c, 2008a). For this drug class, both $C_{\max } / \mathrm{MIC}$

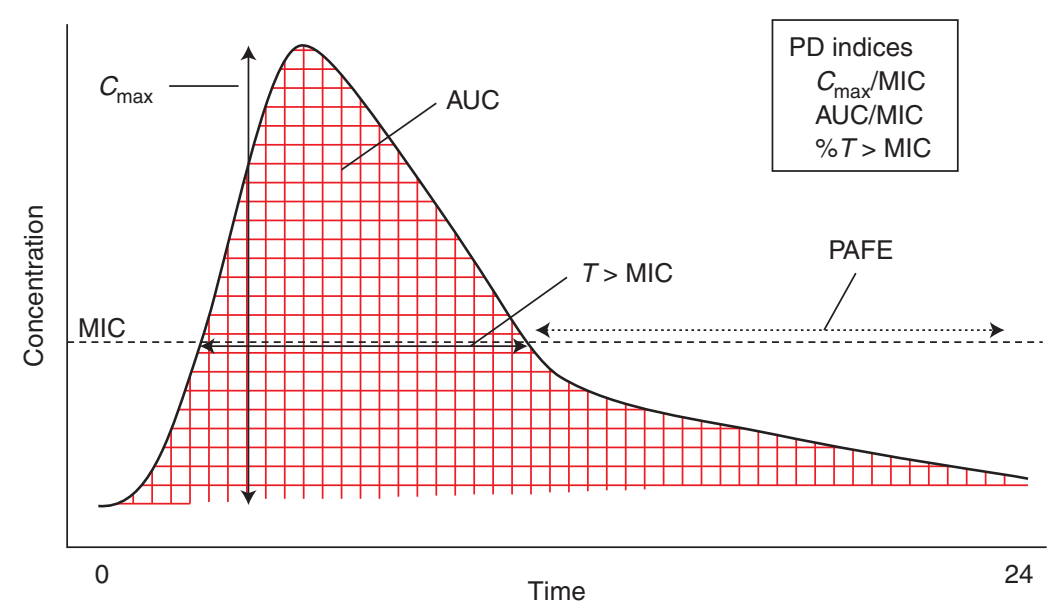

Figure 1. Pharmacokinetic/pharmacodynamic relationship of antimicrobial dosing over time relative to organism MIC. The three PD indices are also listed, including $C_{\max } / \mathrm{MIC}, \mathrm{AUC} / \mathrm{MIC}$, and $\% T>\mathrm{MIC}$. 
Antifungal Pharmacokinetics and Pharmacodynamics

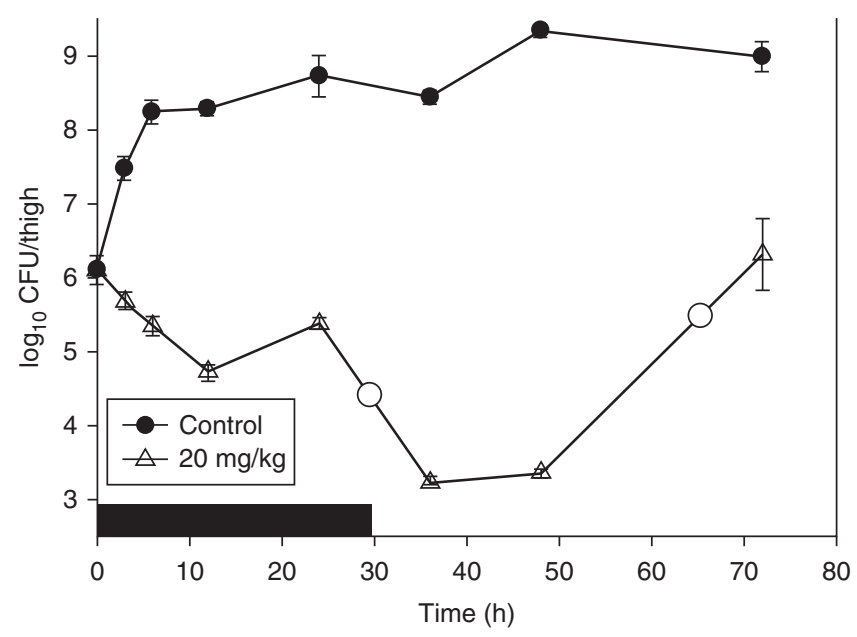

Figure 2. The postantifungal effect. Shown in the figure is a representative example of a drug with a prolonged PAFE. Represented by solid circles is the growth of organism from the thighs of untreated infected mice (control). In comparison, shown by open triangles is the growth curve of organism from thighs of infected mice treated with a single $20-\mathrm{mg} / \mathrm{kg}$ dose of drug given at time point $0 \mathrm{~h}$. The solid bar represents the time that drug concentrations are expected to exceed the MIC. The open circles represent the time at which drug concentration decreases below the MIC until the point at which 1- $\log _{10}$ growth was observed. This time period (38 h) minus the time period it takes the control group to grow $1 \log _{10}$ (in this case $2.5 \mathrm{~h}$ ) is the PAFE (i.e., $\sim 35.5 \mathrm{~h}$ ).

and AUC/MIC are robust PD indices (Walsh et al. 1991; Andes et al. 2003c, 2008a,b; Louie et al. 2005; Gumbo et al. 2006).

An additional exposure-response variable of significance for determination of the PDlinked measure is the impact of the dosing interval on treatment efficacy (Fig. 4).

The experiment by which the impact of the dosing interval is assessed allows one to reduce interdependence of the three PD indices. For example, if one increases the dose administered from $100 \mathrm{mg} / \mathrm{kg}$ once to $1000 \mathrm{mg} / \mathrm{kg}$ once, all three PD indices will increase proportionally. However, if the total dose over the dosing period is kept constant (as in a fractionation experiment), the interdependence is reduced. In this case, as the interval is increased (e.g., from once daily [q24h] to eight times daily [q3h]), each dose is appropriately decreased to keep the daily (or total dose) the same (Fig. 3; Table 1). Therefore, the AUC is approximately the same for each regimen as the same total daily dose is administered (i.e., the same drug exposure is occurring over the time period). However, as the interval is increased, and therefore the individual drug dose is decreased, the $C_{\max }$ will proportionally decrease as the fractionation is increased. Conversely, time above MIC will increase as the fractionation is increased (Fig. 3). When efficacy is enhanced with shorter dosing intervals, the $\% T>$ MIC is most closely linked to efficacy. Conversely, when treatment effect is optimal when larger doses are administered infrequently, the $C_{\max } / \mathrm{MIC}$ is the predictive index. When outcome is similar among various dosing intervals, typically the AUC/MIC measure is predictive of efficacy (Fig. 4). The strength of these relationships can be further examined with nonlinear regression modeling to provide supportive PK/PD evidence (Fig. 5). Table 2 shows the major PD characteristics by fungal drug class.

The second common PK/PD question simply asks how much drug is needed for the intended effect, expressed as the numerical value of the PD index (AUC/MIC, $C_{\max } / \mathrm{MIC}$, or $\% T$ $>$ MIC). Frequent outcome measures in experimental in vitro and in vivo systems include net stasis (lack of change in burden over the treatment period), 50\% maximal effect, $75 \%$ maximal effect, 90\% maximal effect, and a defined 


\section{A.J. Lepak and D.R. Andes}

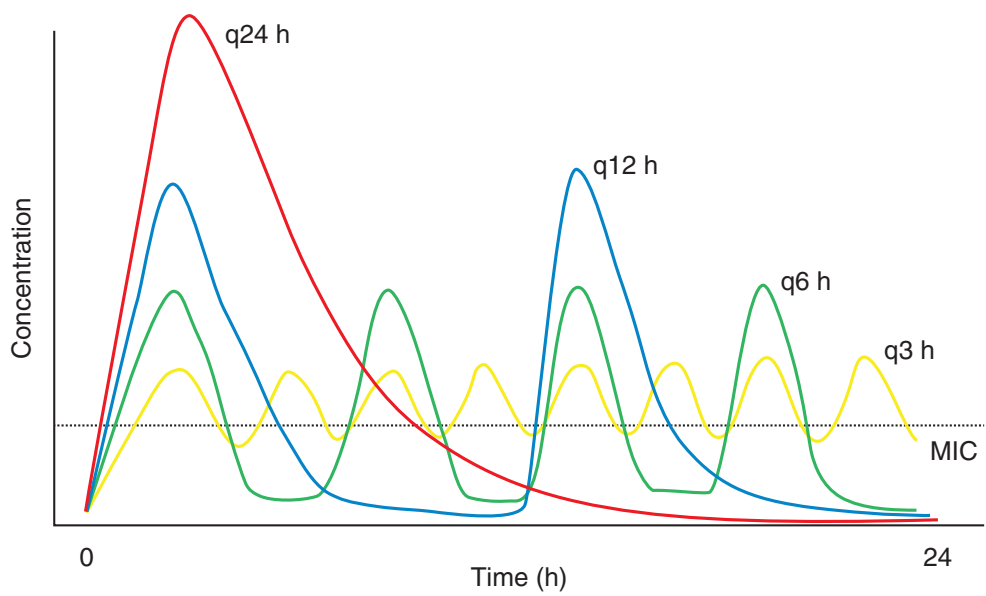

Figure 3. Concentration-time profile showing the effect of fractionating a total daily dose into once-, twice-, four-times-, and eight-times-daily fractions. AUC will remain the same because the total daily dose administered is the same in all four regimens; however, $C_{\max }$ will progressively decline and $\% T>$ MIC will progressively increase as the dose is fractionated into increasing fractions.

reduction in organism burden, such as a 1-log kill or 2-log kill. Which outcome is the most appropriate outcome depends on which correlates with outcome in humans. For invasive candidiasis, this has been well established for triazoles (50\% maximal effect) and echinocandins (stasis). However, for other drug classes and especially for other disease states, such as invasive aspergillosis, the optimal outcome measure in the animal model is unknown. In this case, it is not uncommon for experimental model PD studies to report PD targets for multiple outcome measures, such as net stasis, 1-log kill, and $50 \%$ maximal effect.

\section{Clinical Antifungal PK/PD Determination and Predictions}

The process of translating preclinical PD studies to humans requires validation by analysis of clinical data sets. The optimal data needed to perform these assessments are rare and include a combination of population PKs, an individual organism isolate, MIC, and outcome. There are several examples of data for both mucosal and invasive candidiasis and a single study for aspergillosis that provide this complement of information. These data are reviewed under each drug class below. In addition, there are additional clinical studies that provide solely the PK and outcome portion of these data. The latter can be useful for guiding therapeutic drug monitoring recommendations, which is also discussed below.

When a PD target is validated, the most robust method to bridge predictions to humans is the use of Monte Carlo simulation to optimize dosing regimen design and identify the MIC ceiling (highest MIC) for which the PD target can be achieved (Bradley et al. 2003, 2010; Hope and Drusano 2009). The optimal data sets for these analyses attempt to consider PKvariability

Table 1. Total dose over dosing period

\begin{tabular}{lccccc}
\hline Total dose $(\mathrm{mg} / \mathrm{kg} / 24 \mathrm{~h})$ & Interval & Dose $(\mathrm{mg} / \mathrm{kg})$ administered & AUC $/ \mathrm{MIC}$ & $C_{\max } / \mathrm{MIC}$ & $\% T>\mathrm{MIC}$ \\
\hline 1600 & $\mathrm{q} 24 \mathrm{~h}$ & $1600 \times 1$ & No change & $\uparrow \uparrow \uparrow$ & - \\
1600 & $\mathrm{q} 12 \mathrm{~h}$ & $800 \times 2$ & No change & $\uparrow \uparrow$ & $\uparrow$ \\
1600 & $\mathrm{q} 6 \mathrm{~h}$ & $400 \times 4$ & No change & $\uparrow$ & $\uparrow \uparrow$ \\
1600 & $\mathrm{q} 3 \mathrm{~h}$ & $200 \times 8$ & No change & - & $\uparrow \uparrow \uparrow$ \\
\hline
\end{tabular}


Antifungal Pharmacokinetics and Pharmacodynamics

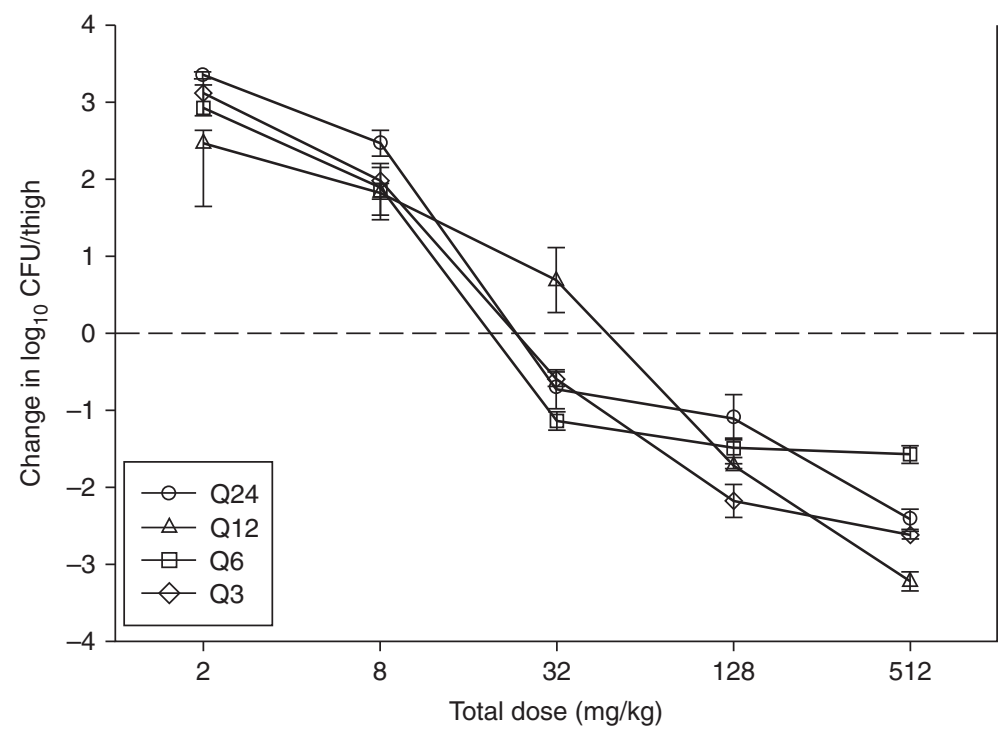

Figure 4. Concentration-effect curves for a dose-fractionation experiment that included four fractionations. The total dose was kept the same for each regimen and is represented on the $x$-axis. Treatment outcome is represented on the $y$-axis as the change in fungal burden from the start of therapy. The dashed line represents net stasis over the duration $(24 \mathrm{~h})$. In this experiment, each of the fractionations essentially overlaps one another, indicating that AUC/MIC, as this is kept constant given that the same total dose is administered, is likely the PD index predictive of efficacy. If $C_{\max }$ was predictive, one would expect the $\mathrm{q} 24 \mathrm{~h}$ regimen to have enhanced effect (i.e., the concentration-effect curve would be significantly lower on the $y$-axis) compared with more fractionated regimens. However, if $\% T>$ MIC was the predictive index, one would expect the $\mathrm{q} 3 \mathrm{~h}$ regimen to have an enhanced effect (i.e., the concentration-effect curve would be significantly lower on the $y$-axis) compared with less fractionated regimens.

by use of population PKs (PK in patients with the disease state under treatment). This process accounts for common factors, such as age, weight, gender, CYP genotype, severity of illness, liver or renal function, and plasma protein levels. Monte Carlo simulation is a process whereby random repeat sampling is performed from a known distribution of PK measures and MIC based on the probability of each measure. In this respect, a small representative sample of patients in whom PK is directly measured can be used to estimate the PK measurements in thousands of patients. This is important because PK sampling and defining the variance in these measurements is impractical to perform on a large scale. The Monte Carlo simulation process occurs by the model program randomly selecting a drug exposure and an MIC from a large population and identifies the probability of $\mathrm{PD}$ target attainment for that drug dose population. The clinician then determines whether this PD target attainment likelihood is acceptable. For example, if a PD target attainment is estimated at $80 \%$ for a Candida urinary tract infection, this may be a reasonable cure rate for an otherwise innocuous disease with little morbidity or mortality. However, an $80 \%$ PD target attainment may not be acceptable for invasive candidiasis, whereby $20 \%$ of the patient population is not receiving therapy that is expected to be adequate. For most serious infectious diseases, a PD target attainment of at least $90 \%$ is considered adequate. The primary goals of this clinical translational tool are to (1) identify drugs and dosing regimens expected to have success for the vast majority of patients, (2) identify drug exposures that may be inadequate, (3) identify alternative dosing strategies to enhance efficacy (such as dose escalation or increased frequency), (4) identify situations in which alternative drugs are necessary, and (5) define clinical susceptibility breakpoints. 
A.J. Lepak and D.R. Andes
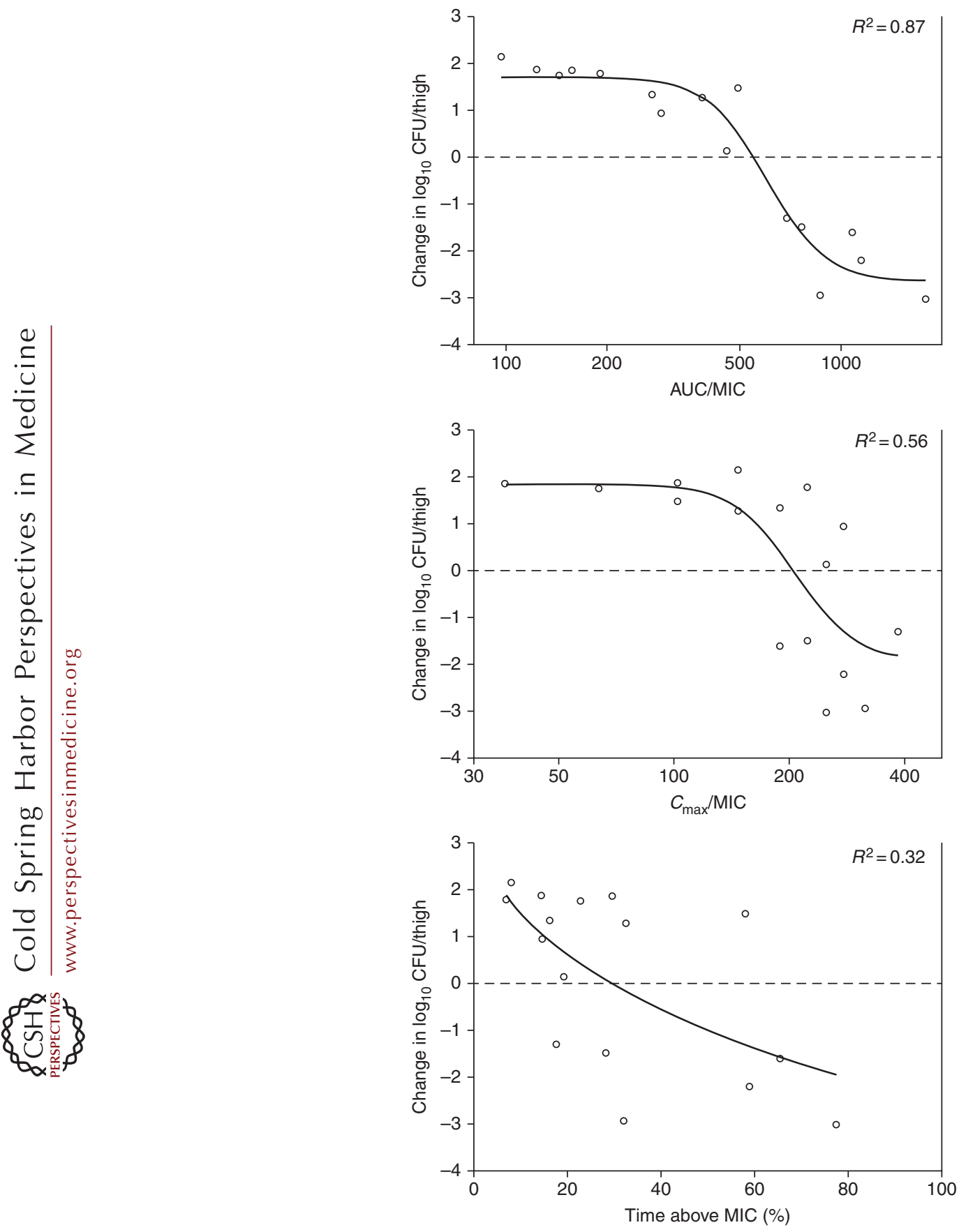

Figure 5. Dose-response curves for each of the three PD indices (displayed on the $x$-axis as AUC/MIC, $C_{\max } /$ MIC, and time above MIC) in a dose-fractionation experiment. Shown on the $y$-axis is the change in organism burden from the start of the experiment, with the dashed line representing net stasis. Points above the dashed line represent an increase in organism burden (i.e., net growth), whereas those below the line represent a decrease in organism burden (i.e., net cidal activity). The curved line represents the best-fit line based on nonlinear regression modeling using the Hill equation (sigmoidal dose-response model) and in the legend is the coefficient of determination $\left(R^{2}\right)$. In the above example, the PD index that best predicts efficacy is AUC/MIC. 
Antifungal Pharmacokinetics and Pharmacodynamics

Table 2. The major PD characteristics by fungal drug class

\begin{tabular}{lccl}
\hline Drug class & Concentration dependent & Prolonged PAFE & PD index predictive of efficacy \\
\hline Polyene & Yes & Yes & $C_{\max } /$ MIC \\
Flucytosine & No & No & $T>$ MIC \\
Azoles & No & Yes & AUC $/$ MIC \\
Echinocandins & Yes & Yes & $C_{\max } /$ MIC or AUC/MIC \\
\hline
\end{tabular}

Monte Carlo simulation has been very helpful to define dosing regimens for difficult-tostudy populations, such as children and neonates, and for certain infections in which the study of different dosing regimens is impractical based on the number of possible regimens or unethical because the study would include suboptimal regimens that cannot be justified (Hope et al. 2007b, 2008, 2010; Ikawa et al. 2009; Warn et al. 2012). For example, studies using the bridging technique of Monte Carlo simulation were performed for neonates and children with hematogenous Candida meningoencephalitis, a rare but well-recognized and potentially lethal infection, with micafungin and anidulafungin (Hope et al. 2010; Warn et al. 2012). In both cases, the recommended dosing strategy would be expected to lead to suboptimal outcome, and therefore higher dosing regimens are recommended.

\section{POLYENES}

\section{Concentration Effect, PD Index, and Target}

The clinically available polyene class consists of conventional deoxycholate amphotericin $\mathrm{B}$ $(\mathrm{AmB})$ and three lipid congeners: liposomal amphotericin B (LAmB), amphotericin B lipid complex (ABLC), and amphotericin B colloidal dispersion (ABCD). In vitro and animal model PD time-kill studies against Candida and filamentous fungi have shown concentration-dependent action as drug dose is escalated multiple times above the MIC (Turnidge et al. 1994; Kelpser et al. 1997; Denning and Warn 1999; Ernst et al. 2000, 2002b; Groll et al. 2000; Warn et al. 2000; Andes et al. 2001, 2006; Vitale et al. 2003; Gavalda et al. 2005; Lewis et al. 2005; Wiederhold et al. 2006; Seyedmousavi et al. 2013a). Long PAFE effects have also been noted, with one study showing a PAFE of almost $1 \mathrm{~d}$
$(>20 \mathrm{~h})$ in a neutropenic mouse model (Turnidge et al. 1994; Ernst et al. 2000; Andes et al. 2001). Dose-fractionation studies have found $C_{\max } / \mathrm{MIC}$ to be the PD index most predictive of efficacy (Andes et al. 2001, 2006). For example, when the dosing frequency was increased from $\mathrm{q} 12 \mathrm{~h}$ to $\mathrm{q} 72 \mathrm{~h}$, the total dose (over $72 \mathrm{~h}$ ) necessary to achieve a net static effect was 10 fold lower in the $\mathrm{q} 72 \mathrm{~h}$ treatment group when given as a single injection compared with the total dose necessary for net stasis when the total dose was fractionated into a $\mathrm{q} 12 \mathrm{~h}$ regimen ( divided doses). The AmB PD target against multiple Candida organisms in a murine model was a $C_{\max } / \mathrm{MIC}$ of 2 for net stasis and 4 for 1-log kill end points. Maximal effects were noted as the $C_{\max } / \mathrm{MIC}$ approached a value of 10 .

AmB PD studies in Aspergillus models are less common; however, studies in vitro and in vivo were congruent with the Candida models (Lewis et al. 2005; Wiederhold et al. 2006). Concentration-dependent action was found, and dose-fractionation study revealed that a significantly lower total dose was required when administered in a single, large dose (q72h) compared with fractionating the total dose into $\mathrm{q} 24 \mathrm{~h}$ or q8h intervals. Both models found that dosing regimens that maximize peak drug concentration exposure were optimal. The $C_{\max } / \mathrm{MIC} \mathrm{PD}$ target in the Aspergillus model was also noted to be maximal at a range of 2-4. Thus, for amphotericin B the PD index and target appear to be relatively similar for both Candida and Aspergillus pathogens.

\section{Amphotericin B Lipid Formulations}

Lipid formulations of amphotericin B (LAmB, $\mathrm{ABLC}$, and $\mathrm{ABCD}$ ) are in general less potent in vivo on a milligrams-per-kilogram basis when compared with AmB. For example, PD studies 
in Candida models with the lipid formulations have shown a four- to sixfold-higher PD target compared with conventional AmB (Andes et al. 2006). Although these formulations are similar in the presence of a lipid component, they are distinct in structure. These differences result in several unique $\mathrm{PK}$ characteristics. One potentially relevant $\mathrm{PK} / \mathrm{PD}$ difference is penetration into certain tissues, such as the CNS. For example, LAmB is composed of small unilamellar particles (liposomes) that exhibit high serum and CNS concentrations in comparison with other lipid preparations (Groll et al. 2000). The relevance of this PK difference was found to be important in a CNS-invasive candidiasis model, whereby the difference in drug concentration in brain parenchyma was closely related to treatment efficacy in favor of LAmB over the other formulations (Groll et al. 2000). Conversely, both ABLC and ABCD achieve much higher concentrations in the intracellular space and in organs of the reticuloendothelial system (Janknegt et al. 1992). In a disseminated candidiasis model, differences in PD potency in the liver, kidney, and lung closely followed the differences in tissue kinetics for each drug in each target organ system (Andes et al. 2006). Several animal model and human investigations have shown that ABLC attains higher concentrations in the lung relative to other formulations (Groll et al. 2006; Lewis et al. 2007). This PK difference was associated with some degree of enhanced efficacy in these models. However, the clinical relevance of these differences remains less clear.

\section{Clinical Implications}

Clinical PD studies of amphotericin B for which PK, MIC, and outcome data are available are limited to a single pediatric cohort (Hong et al. 2006). In this study, a $C_{\max } / \mathrm{MIC}$ ratio of $>40$ was associated with maximal efficacy for a lipid-associated AmB formulation. After accounting for potency differences, this value is relatively similar to the preclinical models that have identified a $C_{\max } / \mathrm{MIC}$ of ratio of 10 as maximally efficacious. Most other studies that have attempted to correlate dose, MIC, and outcome with $\mathrm{AmB}$ have been hampered by the very narrow MIC and dose range, making it very difficult to correlate the PD indices with outcome (Park et al. 2006).

Escalating the dose of amphotericin B, and thus increasing the $C_{\max } / \mathrm{MIC}$, is a strategy that one would presume would increase efficacy given the PD characteristics of this class. This has been investigated to some degree in a prospective clinical study comparing conventional dosing of LAmB $(3-5 \mathrm{mg} / \mathrm{kg} / \mathrm{d})$ to higher initial doses $(10 \mathrm{mg} / \mathrm{kg} / \mathrm{d})$ for the first $14 \mathrm{~d}$ of a proven or probable mold infection (Cornely et al. 2007). However, there was no difference in the outcome with either regimen, although there was decreased toxicity (renal) and decreased rates of drug discontinuation in the low-dose arm. Thus, in this clinical study, increasing drug concentration exposure did not increase efficacy and unfortunately increased adverse effects. The PD explanations for these results include the possibility that (1) the concentration-effect relationship may be maximal at $5 \mathrm{mg} / \mathrm{kg} / \mathrm{d},(2)$ a twoto threefold increase in drug concentration was not enough to discern a meaningful difference in efficacy, or (3) the toxicity of high concentrations outweighed any efficacy benefit. The latter toxicodynamic concept has also been further examined clinically with a suggestion of reduced renal toxicity when amphotericin $B$ has been administered as a continuous infusion compared with once-daily bolus dosing (Eriksson et al. 2001; Imhof et al. 2003; Peleg and Woods 2004; Hall et al. 2005). Unfortunately, these studies were primarily PK based and did not include analysis of this dosing strategy and treatment outcome in patients with proven fungal infection. The PD studies from preclinical models would suggest that this potential toxicodynamic benefit may negatively impact therapeutic efficacy based on lower $C_{\max } / \mathrm{MIC}$ attainment with a continuous-infusion dosing strategy (Seyedmousavi et al. 2013b).

\section{FLUCYTOSINE}

\section{Concentration Effect, PD Index, and Target}

Several studies have examined the effect of escalating concentrations of flucytosine on efficacy 
Antifungal Pharmacokinetics and Pharmacodynamics

against Candida (Turnidge et al. 1994; Andes and van Ogtrop 2000; Lewis et al. 2000; Ernst et al. 2002b; Hope et al. 2006). The results of these studies have shown concentration-independent action with maximal activity at concentrations near the MIC. Additionally, there is rapid regrowth of organism once concentrations decrease below the MIC, and therefore the PAFE is very short. Dose-fractionation studies confirmed the concentration-independent nature of flucytosine, as 10-fold-less total drug was needed for efficacy using the most fractionated dosing strategy (Andes and van Ogtrop 2000). Time course, PAFE, and dose-fractionation studies consistently support $\% T>$ MIC as the most predictive index. Therefore, small but frequent administration of the drug to prolong the $\% T>$ MIC is the optimal dosing strategy for flucytosine. The PD target associated with net stasis from independent animal model studies is a $\% T>$ MIC of $\sim 40 \%$ for invasive candidiasis (Andes and van Ogtrop 2000; Hope et al. 2006). Similar PK/PD studies for Cryptococcus species are limited but do suggest that the current human regimen is sufficient for stasis (O'Connor et al. 2013). This analysis does not provide an estimate of $\% T>$ MIC.

\section{Clinical Implications}

There are no clinical data sets that allow for robust PD efficacy analysis for flucytosine. A single study has bridged animal model PK/PD study of flucytosine to humans (Hope et al. 2006). The investigators integrated flucytosine dose ranges, PKs, and MIC distribution for $C$. albicans. Interestingly, doses as low as $25 \mathrm{mg} /$ $\mathrm{kg} / \mathrm{d}$ (two- to fourfold lower than is currently recommended) would be predicted to achieve the PD target against $C$. albicans given the current $\mathrm{MIC}$ distribution.

Toxicodynamic relationships, however, have been well established from clinical data (Kauffman and Frame 1977; Stamm et al. 1987; Francis and Walsh 1992; Pasqualotto et al. 2007; Smith and Andes 2008). Toxicity of flucytosine therapy has been associated with peak drug concentrations. This makes dosing strategies that maximize $\% T>$ MIC even more attractive as this dosing scheme will also lead to decreased peak ( $\left.C_{\max } / \mathrm{MIC}\right)$ concentrations. Thus, efficacy can be enhanced and toxicity limited by administering low doses very frequently (at least every $6 \mathrm{~h}$ ) to keep drug concentrations above the MIC for $40 \%$.

\section{TRIAZOLES}

\section{Concentration Effect and PD Index and Target}

The azole drug class has undergone the most extensive PD study. Concentration-escalation studies have consistently shown concentration-independent action against Candida species, with maximal growth inhibition at concentrations near the MIC (Ernst et al. 1998, 2002b; Louie et al. 1998; Andes and van Ogtrop 1999; Andes et al. 2003a,b, 2004; Warn et al. 2009). For example, in a dose-escalation in vitro experiment in which the azole drug concentration was varied from sub-MIC levels to more than 200-fold in excess of the MIC, the growth of Candida was similarly inhibited once levels exceeded the MIC. In vivo animal models have also shown maximal growth inhibition associated with concentrations near the MIC. However, these in vivo studies also reveal prolonged PAFEs (Andes and van Ogtrop 1999; Andes et al. 2003a,b, 2004). The integration of concentration-independent action with prolonged PAFE would suggest that AUC/MIC is the PD index most closely associated with efficacy, which has been validated in dose-fractionation studies (Louie et al. 1998; Andes and van Ogtrop 1999; Andes et al. 2003a,b, 2004).

PD target studies have been performed in a number of models that have included Candida, Aspergillus, and Cryptococcus as the infecting pathogens. PK/PD studies have been undertaken with five triazoles in therapy for invasive candidiasis. The PD target for a treatment outcome (defined as a 50\% maximal effect) against Candida species in these studies has consistently been found to be a free-drug AUC/MIC of 25-50 (Andes and van Ogtrop 1999; Andes et al. 2003a,b, 2004; Lepak et al. 2013d). This would mean that drug concentrations that re- 
main near the MIC over a 24-h period would be expected to achieve this target $(1 \times$ MIC $\times$ $24 \mathrm{~h}=\mathrm{AUC} / \mathrm{MIC}$ of 24). There are a number of interesting observations from these studies. First, the PD index predictive of efficacy is similar for drugs within a class as long as freedrug (non-protein-bound) concentrations are considered. Second, the PD target is remarkably similar against different Candida albicans, Candida tropicalis, and Candida krusei species. Additionally, the PD target was congruent across levels of resistance and resistance mechanisms.

PD target measure in Aspergillus animal models has also been recently reported. Interestingly, although azoles are static against Candida, they show marked killing activity against Aspergillus species. At optimal dosing levels, one can see up to 4-log reduction in organism burden in murine pneumonia models (Lepak et al. 2013c). Similar to Candida, there is a very strong relationship between treatment efficacy and the PD index AUC/MIC (Mavridou et al. 2010a,b; Howard et al. 2011; Lepak et al. 2013a,c). This finding affirms that the PK/PD measure linked to efficacy is similar across fungal genera. However, the PD targets associated with efficacy were significantly lower for Aspergillus-active azoles in models that have included both disseminated infection by tail-vein injection of the organism and invasive pulmonary models. The PD target free-drug AUC/MIC for Aspergillus associated with either $\mathrm{ED}_{50}$ or net stasis targets was only 1.7-11 (Mavridou et al. 2010a,b; Howard et al. 2011; Lepak et al. 2013a,c). Perhaps this lower PD target is a result of the more differential fungicidal activity against Aspergillus species. Similar to the Candida studies, the PD target for Aspergillus studies was similar for drug-susceptible and drugresistant strains.

An additional study has examined the fluconazole PD target in a murine cryptococcal meningitis model (Sudan et al. 2013). Therapy against a group of three Cryptococcus neoformans isolates produced a stasis end point with a fluconazole AUC/MIC value near 400, which, interestingly, is higher than is observed for other pathogens.

\section{Clinical Implications}

Although clinical PK/PD data sets are in general uncommon, there is a relatively large experience with fluconazole and voriconazole (Rex et al. 1997; Lee et al. 2000; Takakura et al. 2004; Clancy et al. 2005; Pfaller et al. 2006; Pai et al. 2007; Rodríguez-Tudela et al. 2007; Baddley et al. 2008). In a study of $>1000$ patients receiving fluconazole for oropharyngeal candidiasis, clinical success was noted in $91 \%-100 \%$ of patients in whom the free-drug AUC/MIC was $>25$, whereas it was only $27 \%-35 \%$ in patients with a free-drug AUC/MIC of $<25$ (Rex et al. 1997). Another study in oropharyngeal disease provides similar results, with $92 \%$ success noted in patients with a free-drug AUC/MIC of $>25$ and only $9 \%$ in those with a free-drug AUC/ MIC of $<25$ (Rodríguez-Tudela et al. 2007). Comparable analysis has been undertaken for invasive candidiasis. In aggregate, the individual studies include fluconazole drug exposure (PK/PD) for $>600$ patients with invasive candidiasis (Rex et al. 1997; Lee et al. 2000; Takakura et al. 2004; Clancy et al. 2005; Baddley et al. 2008). There is a remarkably strong relationship between AUC/MIC and treatment outcome, with a free-drug AUC/MIC target of 25-50 associated with maximal survival. A more contemporary analysis with voriconazole shows congruent results (Pfaller et al. 2006). These studies suggest that efficacy in humans is predicted by the animal model $\mathrm{ED}_{50}$ end point.

Clinical PD analyses for the mold-active triazoles in therapy for Aspergillus are less common. The sole study that includes analysis of PK, MIC, and outcome is with voriconazole (Troke et al.2011). The analysis found that maximal outcome was associated with a troughto-MIC ratio near 2 . There are numerous additional analyses that include PK and outcome (Janknegt et al. 1992; Groll et al. 2006; Lewis et al. 2007; Bradley et al. 2010). The results for voriconazole are congruent and suggest that trough concentrations ranging from $1-2 \mu \mathrm{g} /$ $\mathrm{ml}$ are associated with optimal outcome for invasive aspergillosis. Given the MIC distribution for Aspergillus spp. $\left(\mathrm{MIC}_{90}\right.$ of $\left.1 \mu \mathrm{g} / \mathrm{ml}\right)$, the results are relatively similar to the full $\mathrm{PK} / \mathrm{PD}$ 
analysis. Similar PD analysis based on therapeutic drug monitoring (TDM) is available for itraconazole and posaconazole. The TDM results for these compounds are relatively similar. For treatment of a variety of invasive disease caused by a variety of fungal pathogens, optimal outcome is described with trough concentrations near $1 \mu \mathrm{g} / \mathrm{ml}$ (Andes et al. 2009). These antifungals have also been studied in the setting of prophylaxis. Interestingly, TDM evaluation of both antifungals suggests that the PD target is roughly half of that needed for treatment of documented infection (Boogaerts et al. 1989; Jang et al. 2010; Campoli et al. 2013).

A single clinical PK/PD study has examined the relationship between fluconazole serum and cerebrospinal fluid PK and outcome in cryptococcal meningitis. The relationship between PK and outcome was significant and favored the 800-mg/d-dosing regimen (Manosuthi et al. 2010).

\section{ECHINOCANDINS}

\section{Concentration Effect, PD Index, and Target}

The most recently developed antifungal class is the echinocandins (caspofungin, micafungin, and anidulafungin). As a group they exhibit activity against most common Candida species, with less potency in vitro for $C$. parapsilosis. Both in vitro and animal model studies of invasive candidiasis have revealed pronounced concentration-dependent killing effects with prolonged PAFEs (Groll et al. 2001; Petraitis et al. 2001, 2002; Ernst et al. 2002a; Andes et al. 2003c, 2008a,b; Louie et al. 2005; Gumbo et al. 2006, 2007; Hope et al. 2008). Investigations examining the impact of dose and dosing interval found that five- to nearly eightfold less total drug was necessary to achieve treatment end points in the animal model when large, single doses were used in comparison with fractionating the dose into two to six doses over the study (Andes et al. 2003c; Gumbo et al. 2007). Thus, a dosing strategy that includes infrequent administration of large doses is optimal for the echinocandin class. PD index analysis suggests that both $C_{\max } / \mathrm{MIC}$ and AUC/MIC are linked to treatment efficacy, although there may be a slight advantage to optimizing peak concentration $\left(C_{\max } / \mathrm{MIC}\right.$ ) (Andes et al. 2003c, 2008a,b; Louie et al. 2005). An interesting observation with the echinocandin class in experimental studies against Candida and Aspergillus is a concentration-effect ceiling, above which reduced activity and paradoxical growth are observed (Stevens et al. 2004, 2005, 2006; Clemons et al. 2006; Fortwendel et al. 2010). This observation, though, has not been universally noted for all echinocandins, species, or strains, and mechanistically appears complex (Vanstraelen et al. 2013). It is postulated that cell wall compensatory mechanisms and stress response pathways are the major factors contributing to this phenomenon. For example, it has been noted in isolates that exhibit paradoxical growth to echinocandins that there is a compensatory up-regulation of the synthesis of the cell wall component chitin (Stevens et al. 2005; Bizerra et al. 2011). A confirmatory study design showed abolition of the paradoxical effect following the addition of a chitin synthase inhibitor to echinocandin therapy (Shields et al. 2011; Szilagyi et al. 2012). The stress response pathways that have been implicated in this phenomenon include protein kinase C (Wiederhold et al. 2005; Shields et al. 2011), the calcineurin pathway (Wiederhold et al. 2005; Shields et al. 2011), the high-osmolarity glycerol response pathway (Popolo et al. 2001), and heat shock protein 90 (Cowen and Lindquist 2005; Kaneko et al. 2009). Interestingly, all of these pathways seem to have a similar end product as they lead to elevated cell wall chitin content (Munro et al. 2007).

The echinocandins also exhibit activity against Aspergillus species, and animal model studies show similar PK/PD characteristics including concentration-dependent effects and efficacy linked to AUC/MIC and $C_{\max } / \mathrm{MIC}$ (Wiederhold et al. 2004; Clemons and Stevens 2006; Lewis et al. 2008, 2011; Lepak et al. 2013b). However, unlike the cidal activity observed against Candida species, drug exposure against Aspergillus results in growth inhibition without significant organism killing. It is theo- 
rized that this lack of killing activity is related to the apparent limitation of drug activity concentrated at the hyphal tips based on morphology analysis following drug exposure (Kurtz et al. 1994).

Studies examining the PD target for the echinocandins have identified species-specific results. Investigations with $C$. albicans in animal models found that a free-drug $C_{\max } / \mathrm{MIC}$ of $>1$ or AUC/MIC of 10-20 was the PD target associated with a stasis end point (Groll et al. 2001; Andes et al. 2003c, 2008a; Louie et al. 2005; Gumbo et al. 2006). Interestingly, similar study with C. parapsilosis and Candida glabrata in the same models found that the echinocandin exposure needed for stasis was two- to threefold lower than for C. albicans (Andes et al. 2008b, 2010). The mechanistic basis for these differences remains unclear. However, it has been hypothesized that the disparity may be associated with the reduced fitness of these non-albicans species in vivo. These observations have led to species-specific susceptibility breakpoints for Candida species (Pfaller et al. 2011a). Although the Candida species has been found to impact treatment response, drug resistance within species does not appear to influence the PD target. Animal model PK/PD studies with wildtype susceptible and drug-resistant $C$. glabrata clinical isolates resulting from a variety of $F k s$ mutations found that a similar AUC/MIC is needed for efficacy (Lepak et al. 2012). This observation is consistent with $\mathrm{PK} / \mathrm{PD}$ observations with azoles in therapy against drugresistant strains. Given the relatively wide therapeutic window with the echinocandins in patients, the potential to escalate drug doses could have important clinical implications given the recent emergence of drug-resistant $C$. glabrata infections (Pfaller et al. 2011b, 2012; Alexander et al. 2013).

$\mathrm{PD}$ target study in the setting of invasive aspergillosis is limited. A single in vivo observation found that a quite high $C_{\max } / \mathrm{MIC}$ (1020) was needed to achieve a stasis end point in monotherapy (Wiederhold et al. 2004). This may not be surprising, though, based on the relatively modest effect echinocandins have as monotherapy against Aspergillus.

\section{Clinical Implications}

Clinical PD studies with the echinocandins have in general revealed results congruent with studies in preclinical animal models. Study from two phase 3 clinical trials of micafungin use in patients with candidemia or invasive candidiasis was recently used for $\mathrm{PK} / \mathrm{PD}$ analysis (Andes et al. 2012). Among the nearly 500 patients, a total drug AUC/MIC of $>3000$ was found to be associated with optimal treatment outcome (98\% success, compared with $84 \%$ in those with an AUC/MIC of <3000). If one considers the protein binding of micafungin $(99.75 \%)$, the free-drug concentration would be $\sim 8$, which is very similar to the PD target identified in preclinical animal models. Interestingly, subgroup analysis based on Candida species identified a 10-fold lower PK/PD target for patients infected with C. parapsilosis, also consistent with the animal model data. In addition to clinical investigation of the amount of echinocandin needed for efficacy, one study sought to explore the impact of dosing interval on treatment outcome. The impact of high-dose, extendedinterval micafungin was compared to the approved daily regimen in patients with esophageal candidiasis. Outcomes were statistically similar with both treatment strategies, consistent with animal model studies linking efficacy to the AUC/MIC index (Andes et al. 2013). Clinical studies in which echinocandin dose levels have been escalated have not identified a paradoxical effect (Pappas et al. 2007; Betts et al. 2009; Shields et al. 2011; Szilagyi et al. 2012; Andes et al. 2013; Elefanti et al. 2013).

\section{PK/PD ANALYSIS OF COMBINATION THERAPY}

An emerging area of study is $\mathrm{PK} / \mathrm{PD}$ analysis of combination therapy. There are a number of fungal infections for which monotherapy yields suboptimal outcomes. In such instances, the study and application of combination therapy is an alternative strategy that has been attempted to enhance outcome. The best example of the utility of combination antifungal therapy is in the treatment of cryptococcal meningitis 
(Perfect et al. 2010), and, until recently, although clinical efficacy was clear with this strategy, formal PK/PD studies were lacking for this infection and drug combination. The PK/PD of LAmB and flucytosine alone and in combination in a murine model of cryptococcal meningoencephalitis was recently reported (O'Connor et al. 2013). Monotherapy LAmB at a dose of $3 \mathrm{mg} / \mathrm{kg} / \mathrm{d}$ and even at the higher dose level at $5 \mathrm{mg} / \mathrm{kg} / \mathrm{d}$ was less effective than the combination with flucytosine at 50 or $100 \mathrm{mg} / \mathrm{kg} / \mathrm{d}$.

The fungal infection that has received the most attention in the area of combination therapy is invasive aspergillosis. A number of in vitro studies have examined combinations of polyene/azole, polyene/echinocandin, and azole/echinocandin (Vazquez 2008; Seyedmousavi et al. 2013c,d). The analysis of these data is conflicting, with some combination experiments revealing enhanced effects, whereas others fail to confirm this. Azoles in combination with echinocandins in theory may provide the most promising combination strategy given that they act at completely distinct sites (the cell membrane and cell wall, respectively). An in vitro PD study of combination therapy with these two classes supports this tenet (Jeans et al. $2012 b$ ). In vivo animal model experiments are also common, but few have been designed to analyze the combination effects from a pharmacodynamic perspective. For example, a number of fixed-dose studies have suggested potential benefits of combination therapy (Kirkpatrick et al. 2002; Petraitis et al. 2003, 2009; Chandrasekar et al. 2004; MacCallum et al. 2005; van de Sande et al. 2009). However, synergistic interaction may not occur at all doses, and therefore combination $\mathrm{PK} / \mathrm{PD}$ analysis requires dose-ranging experiments. An additional in vivo study has incorporated a wide dose-ranging combination therapy design for invasive aspergillosis (Lepak et al. 2013b). Both wild-type and drug-resistant (Cyp51 mutant) Aspergillus isolates were included in the study of echinocandin/azole combination therapy in the neutropenic murine invasive pulmonary aspergillosis model. Combination therapy did not appear to markedly impact outcome against wild-type isolates when the azole drug concentration was optimized. However, striking synergistic results were noted for combinations of posaconazole and caspofungin against azole-resistant isolates. In fact, at maximal synergistic efficacy a $>2-\log _{10}$ increase in microbiological effect was noted in certain combinations in comparison with what would have been predicted. Therefore, combination therapy may be particularly useful in treatment of the azole-resistant (Cyp51 mutant) Aspergillus infections that appear to be emergent in many parts of the world (Snelders et al. 2008).

Combination therapy may be also a useful strategy for mucormycosis, and animal model data suggest utility of polyene/echinocandin therapy against Rhizopus oryzae (Spellberg et al. 2005; Ibrahim et al. 2008). A similar study with polyene/posaconazole combination did not show enhanced efficacy (Ibrahim et al. 2009). This may have been because of the fact that posaconazole shows modest activity against $R$. oryzae, the most common species of mucormycosis (Dannaoui et al. 2003; Barchiesi et al. 2007; Rodriguez et al. 2008; Ibrahim et al. 2009). However, escalation of posaconazole exposure has shown efficacy, and combination with tacrolimus also showed enhanced effect (Rodriguez et al. 2010; Lewis et al. 2013). Continued PD study and analyses are important for future investigation to close knowledge gaps related to therapy for mucormycosis and other emerging fungal pathogens.

\section{CONCLUSIONS}

Application of $\mathrm{PK} / \mathrm{PD}$ principles to antifungal drug therapy has provided an understanding of the relationship between drug exposure and outcome. The results from experimental PK/PD investigations have been critical for designing optimal dosing strategies to improve clinical efficacy while decreasing toxicities. There remain numerous knowledge gaps in the area of combination therapy and PK/PD against emerging fungal pathogens.

\section{REFERENCES}

Alexander BD, Johnson MD, Pfeiffer CD, Jiménez-Ortigosa C, Catania J, Booker R, Castanheira M, Messer SA, Perlin 
A.J. Lepak and D.R. Andes

DS, Pfaller MA. 2013. Increasing echinocandin resistance in Candida glabrata: Clinical failure correlates with presence of FKS mutations and elevated minimum inhibitory concentrations. Clin Infect Dis 56: 1724-1732.

Al-Nakeeb Z, Sudan A, Jeans AR, Gregson L, Goodwin J, Warn PA, Felton TW, Howard SJ, Hope WW. 2012. Pharmacodynamics of itraconazole against Aspergillus fumigatus in an in vitro model of the human alveolus: Perspectives on the treatment of triazole-resistant infection and utility of airway administration. Antimicrob Agents Chemother 56: 4146-4153.

Andes D. 2003a. In vivo pharmacodynamics of antifungal drugs in treatment of candidiasis. Antimicrob Agents Chemother 47: 1179-1186.

Andes D. 2003b. Clinical pharmacodynamics of antifungals. Infect Dis Clin North Am 17: 635-649.

Andes D. 2004. Clinical utility of antifungal pharmacokinetics and pharmacodynamics. Curr Opin Infect Dis 17: 533-540.

Andes D, van Ogtrop M. 1999. Characterization and quantitation of the pharmacodynamics of fluconazole in a neutropenic murine disseminated candidiasis infection model. Antimicrob Agents Chemother 43: 2116-2120.

Andes D, van Ogtrop M. 2000. In vivo characterization of the pharmacodynamics of flucytosine in a neutropenic murine disseminated candidiasis model. Antimicrob Agents Chemother 44: 938-942.

Andes D, Stamsted T, Conklin R. 2001. Pharmacodynamics of amphotericin B in a neutropenic-mouse disseminated-candidiasis model. Antimicrob Agents Chemother 45: 922-926.

Andes D, Marchillo K, Stamstad T, Conklin R. 2003a. In vivo pharmacokinetics and pharmacodynamics of a new triazole, voriconazole, in a murine candidiasis model. Antimicrob Agents Chemother 47: 3165-3169.

Andes D, Marchillo K, Stamstad T, Conklin R. 2003b. In vivo pharmacodynamics of a new triazole, ravuconazole, in a murine candidiasis model. Antimicrob Agents Chemother 47: 1193-1199.

Andes D, Marchillo K, Lowther J, Bryskier A, Stamstad T, Conklin R. 2003c. In vivo pharmacodynamics of HMR 3270 , a glucan synthase inhibitor, in a murine candidiasis model. Antimicrob Agents Chemother 47: 1187-1192.

Andes D, Marchillo K, Conklin R, Krishna G, Ezzet F, Cacciapuoti A, Loeberg D. 2004. Pharmacodynamics of a new triazole, posaconazole, in a murine model of disseminated candidiasis. Antimicrob Agents Chemother 48: $137-142$.

Andes D, Safdar N, Marchillo K, Conklin R. 2006. Pharmacokinetic-pharmacodynamic comparison of amphotericin $B(A M B)$ and two lipid-associated AMB preparations, liposomal $\mathrm{AMB}$ and $\mathrm{AMB}$ lipid complex, in murine candidiasis models. Antimicrob Agents Chemother 50: 674-684.

Andes D, Diekema DJ, Pfaller MA, Prince RA, Marchillo K, Ashbeck J, Hou J. 2008a. In vivo pharmacodynamic characterization of anidulafungin in a neutropenic murine candidiasis model. Antimicrob Agents Chemother 52: 539-550.

Andes DR, Diekema DJ, Pfaller MA, Marchillo K, Bohrmueller J. 2008b. In vivo pharmacodynamic target investigation for micafungin against Candida albicans and
C. glabrata in a neutropenic murine candidiasis model. Antimicrob Agents Chemother 52: 3497-3503.

Andes D, Pascual A, Marchetti O. 2009. Antifungal therapeutic drug monitoring: Established and emerging indications. Antimicrob Agents Chemother 53: 24-34.

Andes D, Diekema DJ, Pfaller MA, Bohrmuller J, Marchillo $\mathrm{K}$, Lepak A. 2010. In vivo comparison of the pharmacodynamic targets for echinocandin drugs against Candida species. Antimicrob Agents Chemother 54: 2497-2506.

Andes DR, Safdar N, Baddley JW, Playford G, Reboli AC, Rex JH, Sobel JD, Pappas PG, Kullberg BJ; Mycoses Study Group. 2012. Impact of treatment strategy on outcomes in patients with candidemia and other forms of invasive candidiasis: A patient-level quantitative review of randomized trials. Clin Infect Dis 54: 1110-1122.

Andes DR, Reynolds DK, Van Wart SA, Lepak AJ, Kovanda LL, Bhavnani SM. 2013. Clinical pharmacodynamic index identification for micafungin in esophageal candidiasis: Dosing strategy optimization. Antimicrob Agents Chemother 57: 5714-5716.

Baddley JW, Patel M, Bhavnani SM, Moser SA, Andes DR. 2008. Association of fluconazole pharmacodynamics with mortality in patients with candidemia. Antimicrob Agents Chemother 52: 3022-3028.

Barchiesi F, Spreghini E, Santinelli A, Fothergill AW, Pisa E, Giannini D, Rinaldi MG, Scalise G. 2007. Posaconazole prophylaxis in experimental systemic zygomycosis. Antimicrob Agents Chemother 51: 73-77.

Betts RF, Nucci M, Talwar D, Gareca M, Queiroz-Telles F, Bedimo RJ, Herbrecht R, Ruiz-Palacios G, Young JA, Baddley JW, et al. 2009. A Multicenter, double-blind trial of a high-dose caspofungin treatment regimen versus a standard caspofungin treatment regimen for adult patients with invasive candidiasis. Clin Infect Dis 48: 1676-1684.

Bizerra FC, Melo AS, Katchburian E, Freymüller E, Straus AH, Takahashi HK, Colombo AL. 2011. Changes in cell wall synthesis and ultrastructure during paradoxical growth effect of caspofungin on four different Candida species. Antimicrob Agents Chemother 55: 302-310.

Boogaerts MA, Verhoef GE, Zachee P, Demuynck H, Verbist L, De Beule K. 1989. Antifungal prophylaxis with itraconazole in prolonged neutropenia: Correlation with plasma levels. Mycoses 32 (Suppl 1): 103-108.

Bowman JC, Abruzzo GK, Anderson JW, Flattery AM, Gill CJ, Pikounis VB, Schmatz DM, Liberator PA, Douglas CM. 2001. Quantitative PCR assay to measure Aspergillus fumigatus burden in a murine model of disseminated aspergillosis: Demonstration of efficacy of caspofungin acetate. Antimicrob Agents Chemother 45: 3474-3481.

Bradley JS, Dudley MN, Drusano GL. 2003. Predicting efficacy of antiinfectives with pharmacodynamics and Monte Carlo simulation. Pediatr Infect Dis J 22: 982-992; quiz 993-985.

Bradley JS, Garonzik SM, Forrest A, Bhavnani SM. 2010 Pharmacokinetics, pharmacodynamics, and Monte Carlo simulation: Selecting the best antimicrobial dose to treat an infection. Pediatr Infect Dis J 29: 1043-1046.

Brammer KW, Farrow PR, Faulkner JK. 1990. Pharmacokinetics and tissue penetration of fluconazole in humans. Rev Infect Dis 12 (Suppl 3): S318-S326. 
Brock M, Jouvion G, Droin-Bergere S, Dussurget O, Nicola MA, Ibrahim-Granet O. 2008. Bioluminescent Aspergillus fumigatus, a new tool for drug efficiency testing and in vivo monitoring of invasive aspergillosis. Appl Environ Microbiol 74: 7023-7035.

Campoli P, Perlin DS, Kristof AS, White TC, Filler SG, Sheppard DC. 2013. Pharmacokinetics of posaconazole within epithelial cells and fungi: Insights into potential mechanisms of action during treatment and prophylaxis. $J$ Infect Dis 208: $1717-1728$.

Chandrasekar PH, Cutright JL, Manavathu EK. 2004. Efficacy of voriconazole plus amphotericin B or micafungin in a guinea-pig model of invasive pulmonary aspergillosis. Clin Microbiol Infect 10: 925-928.

Chryssanthou E, Cuenca-Estrella M. 2006. Comparison of the EUCAST-AFST broth dilution method with the CLSI reference broth dilution method (M38-A) for susceptibility testing of posaconazole and voriconazole against Aspergillus spp. Clin Microbiol Infect 12: 901-904.

Clancy CJ, Yu VL, Morris AJ, Snydman DR, Nguyen MH. 2005. Fluconazole MIC and the fluconazole dose/ MIC ratio correlate with therapeutic response among patients with candidemia. Antimicrob Agents Chemother 49: 3171-3177.

Clemons KV, Stevens DA. 2006. Efficacy of micafungin alone or in combination against experimental pulmonary aspergillosis. Med Mycol 44: 69-73.

Clemons KV, Espiritu M, Parmar R, Stevens DA. 2006. Assessment of the paradoxical effect of caspofungin in therapy of candidiasis. Antimicrob Agents Chemother 50: 1293-1297.

CLSI. 2004. Method for antifungal disk diffusion susceptibility testing of yeasts: Approved guideline. Clinical and Laboratory Standards Institute, Wayne, PA.

CLSI. 2008a. Reference method for broth dilution antifungal susceptibility testing of yeasts: Approved standard, 3rd ed., No. 14. Clinical and Laboratory Standards Institute, Wayne, PA.

CLSI. 2008b. Reference method for broth dilution antifungal susceptibility testing of filamentous fungi: Approved standard, 2nd ed. Clinical and Laboratory Standards Institute, Wayne, PA.

CLSI. 2008c. Method for antifungal disk diffusion susceptibility testing of filamentous fungi: Proposed guideline. Clinical and Laboratory Standards Institute, Wayne, PA.

Cornely OA, Maertens J, Bresnik M, Ebrahimi R, Ullmann AJ, Bouza E, Heussel CP, Lortholary O, Rieger C, Boehme A, et al. 2007. Liposomal amphotericin B as initial therapy for invasive mold infection: A randomized trial comparing a high-loading dose regimen with standard dosing (AmBiLoad trial). Clin Infect Dis 44: 1289-1297.

Cowen LE, Lindquist S. 2005. Hsp90 potentiates the rapid evolution of new traits: Drug resistance in diverse fungi. Science 309: 2185-2189.

Craig WA. 1998. Pharmacokinetic/pharmacodynamic parameters: Rationale for antibacterial dosing of mice and men. Clin Infect Dis 26: 1-10; quiz 11-12.

Craig WA, Ebert SC. 1989. Protein binding and its significance in antibacterial therapy. Infect Dis Clin North Am 3: $407-414$.
Craig WA, Kunin CM. 1976. Significance of serum protein and tissue binding of antimicrobial agents. Annu Rev Med 27: 287-300.

Craig WA, Vogelman B. 1987. The postantibiotic effect. Ann Intern Med 106: 900-902.

Craig WA, Welling PG. 1977. Protein binding of antimicrobials: Clinical pharmacokinetic and therapeutic implications. Clin Pharmacokinet 2: 252-268.

Dannaoui E, Meis JF, Loebenberg D, Verweij PE. 2003. Activity of posaconazole in treatment of experimental disseminated zygomycosis. Antimicrob Agents Chemother 47: 3647-3650.

Denning DW, Warn P. 1999. Dose range evaluation of liposomal nystatin and comparisons with amphotericin B and amphotericin B lipid complex in temporarily neutropenic mice infected with an isolate of Aspergillus fumigatus with reduced susceptibility to amphotericin B. Antimicrob Agents Chemother 43: 2592-2599.

Drusano GL. 2004. Antimicrobial pharmacodynamics: Critical interactions of "bug and drug." Nat Rev Microbiol 2: 289-300.

Drusano GL. 2007. Pharmacokinetics and pharmacodynamics of antimicrobials. Clin Infect Dis 45 (Suppl 1): S89-S95.

Eagle H, Musselman AD. 1949. The slow recovery of bacteria from the toxic effects of penicillin. J Bacteriol 58: 475490.

Elefanti A, Mouton JW, Krompa K, Al-Saigh R, Verweij PE, Zerva L, Meletiadis J. 2013. Inhibitory and fungicidal effects of antifungal drugs against Aspergillus species in the presence of serum. Antimicrob Agents Chemother 57: $1625-1631$.

Eriksson U, Seifert B, Schaffner A. 2001. Comparison of effects of amphotericin B deoxycholate infused over 4 or 24 hours: Randomised controlled trial. BMJ 322: 579-582.

Ernst EJ, Klepser ME, Pfaller MA. 1998. In vitro interaction of fluconazole and amphotericin B administered sequentially against Candida albicans: Effect of concentration and exposure time. Diagn Microbiol Infect Dis 32: 205210.

Ernst EJ, Klepser ME, Ernst ME, Messer SA, Pfaller MA. 1999. In vitro pharmacodynamic properties of MK0991 determined by time-kill methods. Diagn Microbiol Infect Dis 33: 75-80.

Ernst EJ, Klepser ME, Pfaller MA. 2000. Postantifungal effects of echinocandin, azole, and polyene antifungal agents against Candida albicans and Cryptococcus neoformans. Antimicrob Agents Chemother 44: 1108-1111.

Ernst EJ, Roling EE, Petzold CR, Keele DJ, Klepser ME. 2002a. In vitro activity of micafungin (FK-463) against Candida spp.: Microdilution, time-kill, and postantifungal-effect studies. Antimicrob Agents Chemother 46: 3846-3853.

Ernst EJ, Yodoi K, Roling EE, Klepser ME. 2002b. Rates and extents of antifungal activities of amphotericin $\mathrm{B}$, flucytosine, fluconazole, and voriconazole against Candida lusitaniae determined by microdilution, Etest, and time-kill methods. Antimicrob Agents Chemother 46: $578-581$. 
A.J. Lepak and D.R. Andes

EUCAST. 2008. EUCAST Definitive Document E.Def 9.1: Method for the determination of broth dilution minimum inhibitory concentrations of antifungal agents for conidia forming moulds. European Committee on Antimicrobial Susceptibility Testing, Växjö, Sweden.

EUCAST. 2012. EUCAST Definitive Document E.Def 7.2: Method for the determination of broth dilution minimum inhibitory concentrations of antifungal agents for yeasts. European Committee on Antimicrobial Susceptibility Testing, Växjö, Sweden.

Fisher JF, Sobel JD, Kauffman CA, Newman CA. 2011. Candida urinary tract infections-Treatment. Clin Infect Dis 52 (Suppl 6): S457-S466.

Fortwendel JR, Juvvadi PR, Perfect BZ, Rogg LE, Perfect JR, Steinbach WJ. 2010. Transcriptional regulation of chitin synthases by calcineurin controls paradoxical growth of Aspergillus fumigatus in response to caspofungin. Antimicrob Agents Chemother 54: 1555-1563.

Francesconi A, Kasai M, Petraitiene R, Petraitis V, Kelaher AM, Schaufele R, Hope WW, Shea YR, Bacher J, Walsh TJ. 2006. Characterization and comparison of galactomannan enzyme immunoassay and quantitative realtime PCR assay for detection of Aspergillus fumigatus in bronchoalveolar lavage fluid from experimental invasive pulmonary aspergillosis. J Clin Microbiol 44: 2475-2480.

Francis P, Walsh TJ. 1992. Evolving role of flucytosine in immunocompromised patients: New insights into safety, pharmacokinetics, and antifungal therapy. Clin Infect Dis 15: 1003-1018.

Galiger C, Brock M, Jouvion G, Savers A, Parlato M, Ibrahim-Granet O. 2013. Assessment of efficacy of antifungals against Aspergillus fumigatus: Value of real-time bioluminescence imaging. Antimicrob Agents Chemother 57: 3046-3059.

Gauthier GM, Nork TM, Prince R, Andes D. 2005. Subtherapeutic ocular penetration of caspofungin and associated treatment failure in Candida albicans endophthalmitis. Clin Infect Dis 41: e27-e28.

Gavaldà J, Martín T, López P, Gomis X, Ramírez JL, Rodríguez D, Len O, Puigfel Y, Ruiz I, Pahissa A. 2005. Efficacy of high loading doses of liposomal amphotericin $B$ in the treatment of experimental invasive pulmonary aspergillosis. Clin Microbiol Infect 11: 999-1004.

Gregson L, Hope WW, Howard SJ. 2012. In vitro model of invasive pulmonary aspergillosis in the human alveolus. Methods Mol Biol 845: 361-367.

Groll AH, Giri N, Petraitis V, Petraitiene R, Candelario M, Bacher JS, Piscitelli SC, Walsh TJ. 2000. Comparative efficacy and distribution of lipid formulations of amphotericin B in experimental Candida albicans infection of the central nervous system. J Infect Dis 182: 274-282.

Groll AH, Mickiene D, Petraitiene R, Petraitis V, Lyman CA, Bacher JS, Piscitelli SC, Walsh TJ. 2001. Pharmacokinetic and pharmacodynamic modeling of anidulafungin (LY303366): Reappraisal of its efficacy in neutropenic animal models of opportunistic mycoses using optimal plasma sampling. Antimicrob Agents Chemother 45: 2845-2855.

Groll AH, Lyman CA, Petraitis V, Petraitiene R, Armstrong D, Mickiene D, Alfaro RM, Schaufele RL, Sein T, Bacher J, Walsh TJ. 2006. Compartmentalized intrapulmonary pharmacokinetics of amphotericin B and its lipid formulations. Antimicrob Agents Chemother 50: 3418-3423.

Gumbo T, Drusano GL, Liu W, Ma L, Deziel MR, Drusano MF, Louie A. 2006. Anidulafungin pharmacokinetics and microbial response in neutropenic mice with disseminated candidiasis. Antimicrob Agents Chemother 50: $3695-$ 3700 .

Gumbo T, Drusano GL, Liu W, Kulawy RW, Fregeau C, Hsu V, Louie A. 2007. Once-weekly micafungin therapy is as effective as daily therapy for disseminated candidiasis in mice with persistent neutropenia. Antimicrob Agents Chemother 51: 968-974.

Hall P, Kennedy G, Morton J, Hill GR, Durrant S. 2005. Twenty-four hour continuous infusion of amphotericin $\mathrm{B}$ for the treatment of suspected or proven fungal infection in haematology patients. Intern Med J 35: 374.

Hong Y, Shaw PJ, Nath CE, Yadav SP, Stephen KR, Earl JW, McLachlan AJ. 2006. Population pharmacokinetics of liposomal amphotericin B in pediatric patients with malignant diseases. Antimicrob Agents Chemother 50: 935-942.

Hope WW, Drusano GL. 2009. Antifungal pharmacokinetics and pharmacodynamics: Bridging from the bench to bedside. Clin Microbiol Infect 15: 602-612.

Hope WW, Warn PA, Sharp A, Howard S, Kasai M, Louie A, Walsh TJ, Drusano GL, Denning DW. 2006. Derivation of an in vivo drug exposure breakpoint for flucytosine against Candida albicans and impact of the MIC, growth rate, and resistance genotype on the antifungal effect. Antimicrob Agents Chemother 50: 3680-3688.

Hope WW, Kruhlak MJ, Lyman CA, Petraitiene R, Petraitis V, Francesconi A, Kasai M, Mickiene D, Sein T, Peter J, et al. 2007a. Pathogenesis of Aspergillus fumigatus and the kinetics of galactomannan in an in vitro model of early invasive pulmonary aspergillosis: Implications for antifungal therapy. J Infect Dis 195: 455-466.

Hope WW, Seibel NL, Schwartz CL, Arrieta A, Flynn P, Shad A, Albano E, Keirns JJ, Buell DN, Gumbo T, Drusano GL, Walsh TJ. 2007b. Population pharmacokinetics of micafungin in pediatric patients and implications for antifungal dosing. Antimicrob Agents Chemother 51: 3714-3719.

Hope WW, Mickiene D, Petraitis V, Petraitiene R, Kelaher AM, Hughes JE, Cotton MP, Bacher J, Keirns JJ, Buell D, et al. 2008. The pharmacokinetics and pharmacodynamics of micafungin in experimental hematogenous Candida meningoencephalitis: Implications for echinocandin therapy in neonates. J Infect Dis 197: 163-171.

Hope WW, Smith PB, Arrieta A, Buell DN, Roy M, Kaibara A, Walsh TJ, Cohen-Wolkowiez M, Benjamin DK Jr. 2010. Population pharmacokinetics of micafungin in neonates and young infants. Antimicrob Agents Chemother 54: $2633-2637$.

Howard SJ, Lestner JM, Sharp A, Gregson L, Goodwin J, Slater J, Majithiya JB, Warn PA, Hope WW. 2011. Pharmacokinetics and pharmacodynamics of posaconazole for invasive pulmonary aspergillosis: Clinical implications for antifungal therapy. J Infect Dis 203: 1324-1332.

Ibrahim AS, Gebremariam T, Fu Y, Edwards JE Jr, Spellberg B. 2008. Combination echinocandin-polyene treatment of murine mucormycosis. Antimicrob Agents Chemother 52: $1556-1558$. 
Ibrahim AS, Gebremariam T, Schwartz JA, Edwards JE Jr, Spellberg B. 2009. Posaconazole mono- or combination therapy for treatment of murine zygomycosis. Antimicrob Agents Chemother 53: 772-775.

Ikawa K, Nomura K, Morikawa N, Ikeda K, Taniwaki M. 2009. Assessment of micafungin regimens by pharmacokinetic-pharmacodynamic analysis: A dosing strategy for Aspergillus infections. J Antimicrob Chemother 64: 840844.

Imhof A, Walter RB, Schaffner A. 2003. Continuous infusion of escalated doses of amphotericin B deoxycholate: An open-label observational study. Clin Infect Dis 36: 943-951.

Jang SH, Colangelo PM, Gobburu JV. 2010. Exposure-response of posaconazole used for prophylaxis against invasive fungal infections: Evaluating the need to adjust doses based on drug concentrations in plasma. Clin Pharmacol Ther 88: 115-119.

Janknegt R, de Marie S, Bakker-Woudenberg IA, Crommelin DJ. 1992. Liposomal and lipid formulations of amphotericin B. Clinical pharmacokinetics. Clin Pharmacokinet 23: 279-291.

Jeans AR, Howard SJ, Al-Nakeeb Z, Goodwin J, Gregson L, Majithiya JB, Lass-Flörl C, Cuenca-Estrella M, Arendrup MC, Warn PA, et al. 2012a. Pharmacodynamics of voriconazole in a dynamic in vitro model of invasive pulmonary aspergillosis: Implications for in vitro susceptibility breakpoints. J Infect Dis 206: 442-452.

Jeans AR, Howard SJ, Al-Nakeeb Z, Goodwin J, Gregson L, Warn PA, Hope WW. 2012b. Combination of voriconazole and anidulafungin for treatment of triazole-resistant Aspergillus fumigatus in an in vitro model of invasive pulmonary aspergillosis. Antimicrob Agents Chemother 56: $5180-5185$.

Kaneko Y, Ohno H, Imamura Y, Kohno S, Miyazaki Y. 2009. The effects of an Hsp90 inhibitor on the paradoxical effect. Jpn J Infect Dis 62: 392-393.

Kauffman CA, Frame PT. 1977. Bone marrow toxicity associated with 5-fluorocytosine therapy. Antimicrob Agents Chemother 11: 244-247.

Kirkpatrick WR, Perea S, Coco BJ, Patterson TF. 2002. Efficacy of caspofungin alone and in combination with voriconazole in a guinea pig model of invasive aspergillosis. Antimicrob Agents Chemother 46: 2564-2568.

Klepser ME, Wolfe EJ, Jones RN, Nightingale CH, Pfaller MA. 1997. Antifungal pharmacodynamic characteristics of fluconazole and amphotericin B tested against Candida albicans. Antimicrob Agents Chemother 41: 13921395.

Kunin CM, Craig WA, Kornguth M, Monson R. 1973. Influence of binding on the pharmacologic activity of antibiotics. Ann NY Acad Sci 226: 214-224.

Kurtz MB, Heath IB, Marrinan J, Dreikorn S, Onishi J, Douglas C. 1994. Morphological effects of lipopeptides against Aspergillus fumigatus correlate with activities against (1,3)- $\beta$-D-glucan synthase. Antimicrob Agents Chemother 38: 1480-1489.

Lee SC, Fung CP, Huang JS, Tsai CJ, Chen KS, Chen HY, Lee N, See LC, Shieh WB. 2000. Clinical correlates of antifungal macrodilution susceptibility test results for non-AIDS patients with severe Candida infections treat- ed with fluconazole. Antimicrob Agents Chemother 44: $2715-2718$

Lengerova M, Kocmanova I, Racil Z, Hrncirova K, Pospisilova S, Mayer J, Najvar LK, Wiederhold NP, Kirkpatrick WR, Patterson TF. 2012. Detection and measurement of fungal burden in a guinea pig model of invasive pulmonary aspergillosis by novel quantitative nested real-time PCR compared with galactomannan and (1,3)- $\beta$-D-glucan detection. J Clin Microbiol 50: 602-608.

Lepak A, Castanheira M, Diekema D, Pfaller M, Andes D. 2012. Optimizing echinocandin dosing and susceptibility breakpoint determination via in vivo pharmacodynamic evaluation against Candida glabrata with and without $f k s$ mutations. Antimicrob Agents Chemother 56: $5875-5882$.

Lepak AJ, Marchillo K, Vanhecker J, Andes DR. 2013a. Isavuconazole (BAL4815) pharmacodynamic target determination in an in vivo murine model of invasive pulmonary aspergillosis against wild-type and cyp51 mutant isolates of Aspergillus fumigatus. Antimicrob Agents Chemother 57: 6284-6289.

Lepak AJ, Marchillo K, VanHecker J, Andes DR. 2013b. Impact of in vivo triazole and echinocandin combination therapy for invasive pulmonary aspergillosis: Enhanced efficacy against Cyp51 mutant isolates. Antimicrob Agents Chemother 57: 5438-5447.

Lepak AJ, Marchillo K, Vanhecker J, Andes DR. 2013c. Posaconazole pharmacodynamic target determination against wild-type and Cyp51 mutant isolates of Aspergillus fumigatus in an in vivo model of invasive pulmonary aspergillosis. Antimicrob Agents Chemother 57: 579-585.

Lepak AJ, Marchillo K, VanHecker J, Diekema D, Andes DR. 2013d. Isavuconazole pharmacodynamic target determination for Candida species in an in vivo murine disseminated candidiasis model. Antimicrob Agents Chemother 57: $5642-5648$.

Lewis RE, Lund BC, Klepser ME, Ernst EJ, Pfaller MA. 1998. Assessment of antifungal activities of fluconazole and amphotericin B administered alone and in combination against Candida albicans by using a dynamic in vitro mycotic infection model. Antimicrob Agents Chemother 42: $1382-1386$.

Lewis RE, Klepser ME, Pfaller MA. 2000. In vitro pharmacodynamic characteristics of flucytosine determined by time-kill methods. Diagn Microbiol Infect Dis 36: 101105.

Lewis RE, Wiederhold NP, Klepser ME. 2005. In vitro pharmacodynamics of amphotericin B, itraconazole, and voriconazole against Aspergillus, Fusarium, and Scedosporium spp. Antimicrob Agents Chemother 49: 945-951.

Lewis RE, Liao G, Hou J, Chamilos G, Prince RA, Kontoyiannis DP. 2007. Comparative analysis of amphotericin B lipid complex and liposomal amphotericin B kinetics of lung accumulation and fungal clearance in a murine model of acute invasive pulmonary aspergillosis. Antimicrob Agents Chemother 51: 1253-1258.

Lewis RE, Albert ND, Kontoyiannis DP. 2008. Comparison of the dose-dependent activity and paradoxical effect of caspofungin and micafungin in a neutropenic murine model of invasive pulmonary aspergillosis. J Antimicrob Chemother 61: 1140-1144. 
A.J. Lepak and D.R. Andes

Lewis RE, Liao G, Hou J, Prince RA, Kontoyiannis DP. 2011 Comparative in vivo dose-dependent activity of caspofungin and anidulafungin against echinocandin-susceptible and -resistant Aspergillus fumigatus. J Antimicrob Chemother 66: 1324-1331.

Lewis RE, Ben-Ami R, Best L, Albert N, Walsh TJ, Kontoyiannis DP. 2013. Tacrolimus enhances the potency of posaconazole against Rhizopus oryzae in vitro and in an experimental model of mucormycosis. J Infect Dis 207: 834-841.

Louie A, Drusano GL, Banerjee P, Liu QF, Liu W, Kaw P, Shayegani M, Taber H, Miller MH. 1998. Pharmacodynamics of fluconazole in a murine model of systemic candidiasis. Antimicrob Agents Chemother 42: 11051109.

Louie A, Deziel M, Liu W, Drusano MF, Gumbo T, Drusano GL. 2005. Pharmacodynamics of caspofungin in a murine model of systemic candidiasis: Importance of persistence of caspofungin in tissues to understanding drus activity. Antimicrob Agents Chemother 49: 5058-5068.

MacCallum DM, Whyte JA, Odds FC. 2005. Efficacy of caspofungin and voriconazole combinations in experimental aspergillosis. Antimicrob Agents Chemother 49: 3697 3701.

Manosuthi W, Chetchotisakd P, Nolen TL, Wallace D, Sungkanuparph S, Anekthananon T, Supparatpinyo K, Pappa PG, Larsen RA, Filler SG, et al. 2010. Monitoring and impact of fluconazole serum and cerebrospinal fluid concentration in HIV-associated cryptococcal meningitisinfected patients. HIV Med 11: 276-281.

Mavridou E, Bruggemann RJ, Melchers WJ, Mouton JW, Verweij PE. 2010a. Efficacy of posaconazole against three clinical Aspergillus fumigatus isolates with mutations in the cyp51A gene. Antimicrob Agents Chemother 54: 860 865.

Mavridou E, Bruggemann RJ, Melchers WJ, Verweij PE, Mouton JW. 2010b. Impact of cyp51A mutations on the pharmacokinetic and pharmacodynamic properties of voriconazole in a murine model of disseminated aspergillosis. Antimicrob Agents Chemother 54: 4758-4764.

Meletiadis J, Petraitis V, Petraitiene R, Lin P, Stergiopoulou T, Kelaher AM, Sein T, Schaufele RL, Bacher J, Walsh TJ. 2006. Triazole-polyene antagonism in experimental invasive pulmonary aspergillosis: In vitro and in vivo correlation. J Infect Dis 194: 1008-1018.

Mukherjee PK, Mohamed S, Chandra J, Kuhn D, Liu S, Antar OS, Munyon R, Mitchell AP, Andes D, Chance $\mathrm{MR}$, et al. 2006. Alcohol dehydrogenase restricts the ability of the pathogen Candida albicans to form a biofilm on catheter surfaces through an ethanol-based mechanism. Infect Immun 74: 3804-3816.

Munro CA, Selvaggini S, de Bruijn I, Walker L, Lenardon MD, Gerssen B, Milne S, Brown AJ, Gow NA. 2007. The PKC, $\mathrm{HOG}$ and $\mathrm{Ca}^{2+}$ signalling pathways co-ordinately regulate chitin synthesis in Candida albicans. Mol Microbiol 63: 1399-1413.

O'Connor L, Livermore J, Sharp AD, Goodwin J, Gregson L, Howard SJ, Felton TW, Schwartz JA, Neely MN, Harrison TS, et al. 2013. Pharmacodynamics of liposomal amphotericin B and flucytosine for cryptococcal meningoencephalitis: Safe and effective regimens for immunocompromised patients. J Infect Dis 208: 351-361.
Pai MP, Turpin RS, Garey KW. 2007. Association of fluconazole area under the concentration-time curve/MIC and dose/MIC ratios with mortality in nonneutropenic patients with candidemia. Antimicrob Agents Chemother 51: 35-39.

Pappas PG, Rotstein CM, Betts RF, Nucci M, Talwar D, De Waele JJ, Vazquez JA, Dupont BF, Horn DL, OstroskyZeichner L, et al. 2007. Micafungin versus caspofungin for treatment of candidemia and other forms of invasive candidiasis. Clin Infect Dis 45: 883-893.

Park BJ, Arthington-Skaggs BA, Hajjeh RA, Iqbal N, Ciblak MA, Lee-Yang W, Hairston MD, Phelan M, Plikaytis BD, Sofair AN, et al. 2006. Evaluation of amphotericin B interpretive breakpoints for Candida bloodstream isolates by correlation with therapeutic outcome. Antimicrob Agents Chemother 50: 1287-1292.

Pasqualotto AC, Howard SJ, Moore CB, Denning DW. 2007. Flucytosine therapeutic monitoring: 15 years experience from the UK. J Antimicrob Chemother 59: 791-793.

Peleg AY, Woods ML. 2004. Continuous and $4 \mathrm{~h}$ infusion of amphotericin B: A comparative study involving high-risk haematology patients. J Antimicrob Chemother 54: 803808.

Perfect JR, Savani DV, Durack DT. 1986. Comparison of itraconazole and fluconazole in treatment of cryptococcal meningitis and candida pyelonephritis in rabbits. Antimicrob Agents Chemother 29: 579-583.

Perfect JR, Dismukes WE, Dromer F, Goldman DL, Graybill JR, Hamill RJ, Harrison TS, Larsen RA, Lortholary O, Nguyen MH, et al. 2010. Clinical practice guidelines for the management of cryptococcal disease: 2010 update by the Infectious Diseases Society of America. Clin Infect Dis 50: $291-322$.

Petraitiene R, Petraitis V, Groll AH, Sein T, Piscitelli S, Candelario M, Field-Ridley A, Avila N, Bacher J, Walsh TJ. 2001. Antifungal activity and pharmacokinetics of posaconazole (SCH 56592) in treatment and prevention of experimental invasive pulmonary aspergillosis: Correlation with galactomannan antigenemia. Antimicrob Agents Chemother 45: 857-869.

Petraitiene R, Petraitis V, Groll AH, Sein T, Schaufele RL, Francesconi A, Bacher J, Avila NA, Walsh TJ. 2002. Antifungal efficacy of caspofungin (MK-0991) in experimental pulmonary aspergillosis in persistently neutropenic rabbits: Pharmacokinetics, drug disposition, and relationship to galactomannan antigenemia. Antimicrob Agents Chemother 46: 12-23.

Petraitis V, Petraitiene R, Groll AH, Bell A, Callender DP, Sein T, Schaufele RL, McMillian CL, Bacher J, Walsh TJ 1998. Antifungal efficacy, safety, and single-dose pharmacokinetics of LY303366, a novel echinocandin B, in experimental pulmonary aspergillosis in persistently neutropenic rabbits. Antimicrob Agents Chemother 42: 2898-2905.

Petraitis V, Petraitiene R, Groll AH, Sein T, Schaufele RL, Lyman CA, Francesconi A, Bacher J, Piscitelli SC, Walsh TJ. 2001. Dosage-dependent antifungal efficacy of Vechinocandin (LY303366) against experimental fluconazole-resistant oropharyngeal and esophageal candidiasis. Antimicrob Agents Chemother 45: 471-479.

Petraitis V, Petraitiene R, Groll AH, Roussillon K, Hemmings M, Lyman CA, Sein T, Bacher J, Bekersky I, Walsh 
TJ. 2002. Comparative antifungal activities and plasma pharmacokinetics of micafungin (FK463) against disseminated candidiasis and invasive pulmonary aspergillosis in persistently neutropenic rabbits. Antimicrob Agents Chemother 46: 1857-1869.

Petraitis V, Petraitiene R, Sarafandi AA, Kelaher AM, Lyman CA, Casler HE, Sein T, Groll AH, Bacher J, Avila NA, et al. 2003. Combination therapy in treatment of experimental pulmonary aspergillosis: Synergistic interaction between an antifungal triazole and an echinocandin. J Infect Dis 187: $1834-1843$

Petraitis V, Petraitiene R, Solomon J, Kelaher AM, Murray HA, Mya-San C, Bhandary AK, Sein T, Avila NA, Basevicius A, et al. 2006. Multidimensional volumetric imaging of pulmonary infiltrates for measuring therapeutic response to antifungal therapy in experimental invasive pulmonary aspergillosis. Antimicrob Agents Chemother 50: $1510-1517$.

Petraitis V, Petraitiene R, Hope WW, Meletiadis J, Mickiene D, Hughes JE, Cotton MP, Stergiopoulou T, Kasai M, Francesconi A, et al. 2009. Combination therapy in treatment of experimental pulmonary aspergillosis: In vitro and in vivo correlations of the concentration- and dosedependent interactions between anidulafungin and voriconazole by Bliss independence drug interaction analysis. Antimicrob Agents Chemother 53: 2382-2391.

Pfaller MA, Diekema DJ. 2012. Progress in antifungal susceptibility testing of Candida spp. by use of Clinical and Laboratory Standards Institute broth microdilution methods, 2010 to 2012. J Clin Microbiol 50: 2846-2856.

Pfaller MA, Diekema DJ, Rex JH, Espinel-Ingroff A, Johnson EM, Andes D, Chaturvedi V, Ghannoum MA, Odds FC, Rinaldi MG, et al. 2006. Correlation of MIC with outcome for Candida species tested against voriconazole: Analysis and proposal for interpretive breakpoints. $J$ Clin Microbiol 44: 819-826.

Pfaller MA, Diekema DJ, Andes D, Arendrup MC, Brown SD, Lockhart SR, Motyl M, Perlin DS, CLSI Subcommittee for Antifungal Testing. 2011a. Clinical breakpoints for the echinocandins and Candida revisited: Integration of molecular, clinical, and microbiological data to arrive at species-specific interpretive criteria. Drug Resist Updat 14: $164-176$.

Pfaller MA, Messer SA, Moet GJ, Jones RN, Castanheira M. 2011b. Candida bloodstream infections: Comparison of species distribution and resistance to echinocandin and azole antifungal agents in Intensive Care Unit (ICU) and non-ICU settings in the SENTRY Antimicrobial Surveillance Program (2008-2009). Int J Antimicrob Agents 38: 65-69.

Pfaller MA, Castanheira M, Lockhart SR, Ahlquist AM, Messer SA, Jones RN. 2012. Frequency of decreased susceptibility and resistance to echinocandins among fluconazole-resistant bloodstream isolates of Candida glabrata. J Clin Microbiol 50: 1199-1203.

Popolo L, Gualtieri T, Ragni E. 2001. The yeast cell-wall salvage pathway. Med Mycol 39 (Suppl 1): 111-121.

Purkins L, Wood N, Ghahramani P, Greenhalgh K, Allen MJ, Kleinermans D. 2002. Pharmacokinetics and safety of voriconazole following intravenous- to oral-dose escalation regimens. Antimicrob Agents Chemother 46: 25462553.
Rex JH, Pfaller MA, Galgiani JN, Bartlett MS, Espinel-Ingroff A, Ghannoum MA, Lancaster M, Odds FC, Rinaldi MG, Walsh TJ, Barry AL. 1997. Development of interpretive breakpoints for antifungal susceptibility testing: Conceptual framework and analysis of in vitro-in vivo correlation data for fluconazole, itraconazole, and candida infections. Subcommittee on Antifungal Susceptibility Testing of the National Committee for Clinical Laboratory Standards. Clin Infect Dis 24: 235-247.

Riddell J IV, Comer GM, Kauffman CA. 2011. Treatment of endogenous fungal endophthalmitis: Focus on new antifungal agents. Clin Infect Dis 52: 648-653.

Rodriguez MM, Serena C, Marine M, Pastor FJ, Guarro J. 2008. Posaconazole combined with amphotericin B, an effective therapy for a murine disseminated infection caused by Rhizopus oryzae. Antimicrob Agents Chemother 52: 3786-3788.

Rodriguez MM, Pastor FJ, Sutton DA, Calvo E, Fothergill AW, Salas V, Rinaldi MG, Guarro J. 2010. Correlation between in vitro activity of posaconazole and in vivo efficacy against Rhizopus oryzae infection in mice. Antimicrob Agents Chemother 54: 1665-1669.

Rodríguez-Tudela JL, Almirante B, Rodríguez-Pardo D, Laguna F, Donnelly JP, Mouton JW, Pahissa A, Cuenca-Estrella M. 2007. Correlation of the MIC and dose/MIC ratio of fluconazole to the therapeutic response of patients with mucosal candidiasis and candidemia. Antimicrob Agents Chemother 51: 3599-3604.

Rodvold KA, George JM, Yoo L. 2011. Penetration of antiinfective agents into pulmonary epithelial lining fluid: Focus on antibacterial agents. Clin Pharmacokinet 50: 637-664.

Savani DV, Perfect JR, Cobo LM, Durack DT. 1987. Penetration of new azole compounds into the eye and efficacy in experimental Candida endophthalmitis. Antimicrob Agents Chemother 31: 6-10.

Schwartz S, Reisman A, Troke PF. 2011. The efficacy of voriconazole in the treatment of 192 fungal central nervous system infections: A retrospective analysis. Infection 39: 201-210.

Seyedmousavi S, Melchers WJ, Mouton JW, Verweij PE. 2013a. Pharmacodynamics and dose-response relationships of liposomal amphotericin B against different azole-resistant Aspergillus fumigatus isolates in a murine model of disseminated aspergillosis. Antimicrob Agents Chemother 57: 1866-1871.

Seyedmousavi S, Mouton JW, Verweij PE, Andes DR. 2013b. Continuous infusion of amphotericin B deoxycholate for the treatment of life-threatening Candida infections. Am J Respir Crit Care Med 188: 1033.

Seyedmousavi S, Meletiadis J, Melchers WJ, Rijs AJ, Mouton JW, Verweij PE. 2013c. In vitro interaction of voriconazole and anidulafungin against triazole-resistant Aspergillus fumigatus. Antimicrob Agents Chemother 57: 796803.

Seyedmousavi S, Bruggemann RJ, Melchers WJ, Rijs AJ, Verweij PE, Mouton JW. 2013d. Efficacy and pharmacodynamics of voriconazole combined with anidulafungin in azole-resistant invasive aspergillosis. J Antimicrob Chemother 68: 385-393.

Sheppard DC, Marr KA, Fredricks DN, Chiang LY, Doedt T, Filler SG. 2006. Comparison of three methodologies for 
A.J. Lepak and D.R. Andes

the determination of pulmonary fungal burden in experimental murine aspergillosis. Clin Microbiol Infect 12: $376-380$.

Shields RK, Nguyen MH, Du C, Press E, Cheng S, Clancy CJ. 2011. Paradoxical effect of caspofungin against Candida bloodstream isolates is mediated by multiple pathways but eliminated in human serum. Antimicrob Agents Chemother 55: 2641-2647.

Smith J, Andes D. 2008. Therapeutic drug monitoring of antifungals: Pharmacokinetic and pharmacodynamic considerations. Ther Drug Monit 30: 167-172.

Snelders E, van der Lee HA, Kuijpers J, Rijs AJ, Varga J, Samson RA, Mellado E, Donders AR, Melchers WJ, Verweij PE. 2008. Emergence of azole resistance in Aspergillus fumigatus and spread of a single resistance mechanism. PLoS Med 5: e219.

Spellberg B, Fu Y, Edwards JE Jr, Ibrahim AS. 2005. Combination therapy with amphotericin B lipid complex and caspofungin acetate of disseminated zygomycosis in diabetic ketoacidotic mice. Antimicrob Agents Chemother 49: 830-832.

Stamm AM, Diasio RB, Dismukes WE, Shadomy S, Cloud GA, Bowles CA, Karam GH, Espinel-Ingroff A. 1987. Toxicity of amphotericin B plus flucytosine in $194 \mathrm{pa}-$ tients with cryptococcal meningitis. Am J Med 83: 236242.

Stevens DA, Espiritu M, Parmar R. 2004. Paradoxical effect of caspofungin: Reduced activity against Candida albicans at high drug concentrations. Antimicrob Agents Chemother 48: 3407-3411.

Stevens DA, White TC, Perlin DS, Selitrennikoff CP. 2005. Studies of the paradoxical effect of caspofungin at high drug concentrations. Diagn Microbiol Infect Dis 51: 173178.

Stevens DA, Ichinomiya M, Koshi Y, Horiuchi H. 2006. Escape of Candida from caspofungin inhibition at concentrations above the MIC (paradoxical effect) accomplished by increased cell wall chitin: Evidence for $\beta-1,6-$ glucan synthesis inhibition by caspofungin. Antimicrob Agents Chemother 50: 3160-3161.

Sudan A, Livermore J, Howard SJ, Al-Nakeeb Z, Sharp A, Goodwin J, Gregson L, Warn PA, Felton TW, Perfect JR, et al. 2013. Pharmacokinetics and pharmacodynamics of fluconazole for cryptococcal meningoencephalitis: Implications for antifungal therapy and in vitro susceptibility breakpoints. Antimicrob Agents Chemother 57: 2793-2800.

Sun HY, Alexander BD, Lortholary O, Dromer F, Forrest GN, Lyon GM, Somani J, Gupta KL, del Busto R, Pruett TL, et al. 2009. Lipid formulations of amphotericin B significantly improve outcome in solid organ transplant recipients with central nervous system cryptococcosis. Clin Infect Dis 49: 1721-1728.

Szilagyi J, Foldi R, Bayegan S, Kardos G, Majoros L. 2012. Effect of nikkomycin $Z$ and $50 \%$ human serum on the killing activity of high-concentration caspofungin against Candida species using time-kill methodology. J Chemotherapy 24: 18-25.

Takakura S, Fujihara N, Saito T, Kudo T, Iinuma Y, Ichiyama S, Japan Invasive Mycosis Surveillance Study Group. 2004. Clinical factors associated with fluconazole resistance and short-term survival in patients with Candida bloodstream infection. Eur J Clin Microbiol Infect Dis 23: 380-388.

Te Dorsthorst DT, Verweij PE, Meis JF, Punt NC, Mouton JW. 2013. In vitro interactions between amphotericin B, itraconazole, and flucytosine against 21 clinical Aspergillus isolates determined by two drug interaction models. Antimicrob Agents Chemother 48: 2007-2013.

Troke PF, Hockey HP, Hope WW. 2011. Observational study of the clinical efficacy of voriconazole and its relationship to plasma concentrations in patients. Antimicrob Agents Chemother 55: 4782-4788.

Turnidge JD, Gudmundsson S, Vogelman B, Craig WA. 1994. The postantibiotic effect of antifungal agents against common pathogenic yeasts. J Antimicrob Chemother 34: 83-92.

Utz JP. 1975. New drugs for the systemic mycoses: Flucytosine and clotrimazole. Bull NYAcad Med 51: 1103-1108.

Vallor AC, Kirkpatrick WR, Najvar LK, Bocanegra R, Kinney MC, Fothergill AW, Herrera ML, Wickes BL, Graybill JR, Patterson TF. 2008. Assessment of Aspergillus fumigatus burden in pulmonary tissue of guinea pigs by quantitative PCR, galactomannan enzyme immunoassay, and quantitative culture. Antimicrob Agents Chemother 52: 2593-2598.

van de Sande WW, Mathot RA, ten Kate MT, van Vianen W, Tavakol M, Rijnders BJ, Bakker-Woudenberg IA. 2009. Combination therapy of advanced invasive pulmonary aspergillosis in transiently neutropenic rats using human pharmacokinetic equivalent doses of voriconazole and anidulafungin. Antimicrob Agents Chemother 53: 20052013.

Vanstraelen K, Lagrou K, Maertens J, Wauters J, Willems L, Spriet I. 2013. The Eagle-like effect of echinocandins: What's in a name? Expert Rev Anti Infect Ther 11: 1179-1191.

Vazquez JA. 2008. Clinical practice: Combination antifungal therapy for mold infections: Much ado about nothing? Clin Infect Dis 46: 1889-1901.

Vitale RG, Meis JF, Mouton JW, Verweij PE. 2003. Evaluation of the post-antifungal effect (PAFE) of amphotericin $B$ and nystatin against 30 zygomycetes using two different media. J Antimicrob Chemother 52: 65-70.

Vogelman BS, Craig WA. 1985. Postantibiotic effects. J Antimicrob Chemother 15 (Suppl A): 37-46.

Vogelman B, Gudmundsson S, Turnidge J, Leggett J, Craig WA. 1988. In vivo postantibiotic effect in a thigh infection in neutropenic mice. J Infect Dis 157: 287-298.

Walsh TJ, Lee JW, Kelly P, Bacher J, Lecciones J, Thomas V, Lyman C, Coleman D, Gordee R, Pizzo PA. 1991. Antifungal effects of the nonlinear pharmacokinetics of cilofungin, a $1,3-\beta$-glucan synthetase inhibitor, during continuous and intermittent intravenous infusions in treatment of experimental disseminated candidiasis. Antimicrob Agents Chemother 35: 1321-1328.

Walsh TJ, Petraitis V, Petraitiene R, Solomon J, Bacher JD, Greene L, Cotton M, Groll A, Roilides E, Avila N, et al. 2009. Diagnostic imaging of experimental invasive pulmonary aspergillosis. Med Mycol 47 (Suppl 1): S138S145.

Wanger A, Mills K, Nelson PW, Rex JH. 1995. Comparison of Etest and National Committee for Clinical Laboratory Standards broth macrodilution method for antifungal 
Antifungal Pharmacokinetics and Pharmacodynamics

susceptibility testing: Enhanced ability to detect amphotericin B-resistant Candida isolates. Antimicrob Agents Chemother 39: 2520-2522.

Warn PA, Morrissey J, Moore CB, Denning DW. 2000. In vivo activity of amphotericin B lipid complex in immunocompromised mice against fluconazole-resistant or fluconazole-susceptible Candida tropicalis. Antimicrob Agents Chemother 44: 2664-2671.

Warn PA, Sharp A, Parmar A, Majithiya J, Denning DW, Hope WW. 2009. Pharmacokinetics and pharmacodynamics of a novel triazole, isavuconazole: Mathematical modeling, importance of tissue concentrations, and impact of immune status on antifungal effect. Antimicrob Agents Chemother 53: 3453-3461.

Warn PA, Livermore J, Howard S, Felton TW, Sharp A, Gregson L, Goodwin J, Petraitiene R, Petraitis V, Cohen-Wolkowiez M, et al. 2012. Anidulafungin for neonatal hematogenous Candida meningoencephalitis: Identification of candidate regimens for humans using a translational pharmacological approach. Antimicrob Agents Chemother 56: 708-714.

Wiederhold NP, Kontoyiannis DP, Chi J, Prince RA, Tam VH, Lewis RE. 2004. Pharmacodynamics of caspofungin in a murine model of invasive pulmonary aspergillosis:
Evidence of concentration-dependent activity. J Infect Dis 190: 1464-1471.

Wiederhold NP, Kontoyiannis DP, Prince RA, Lewis RE. 2005. Attenuation of the activity of caspofungin at high concentrations against Candida albicans: Possible role of cell wall integrity and calcineurin pathways. Antimicrob Agents Chemother 49: 5146-5148.

Wiederhold NP, Tam VH, Chi J, Prince RA, Kontoyiannis DP, Lewis RE. 2006. Pharmacodynamic activity of amphotericin $B$ deoxycholate is associated with peak plasma concentrations in a neutropenic murine model of invasive pulmonary aspergillosis. Antimicrob Agents Chemother 50: 469-473.

Wiederhold NP, Najvar LK, Vallor AC, Kirkpatrick WR, Bocanegra R, Molina D, Olivo M, Graybill JR, Patterson TF. 2008 . Assessment of serum $(1 \rightarrow 3)$ - $\beta$-D-glucan concentration as a measure of disease burden in a murine model of invasive pulmonary aspergillosis. Antimicrob Agents Chemother 52: 1176-1178.

Zeitlinger MA, Derendorf H, Mouton JW, Cars O, Craig WA, Andes D, Theuretzbacher U. 2011. Protein binding: Do we ever learn? Antimicrob Agents Chemother 55: 30673074 . 


\section{$\&_{\mathrm{CSH}}^{\infty} \&$ Cold Spring Harbor

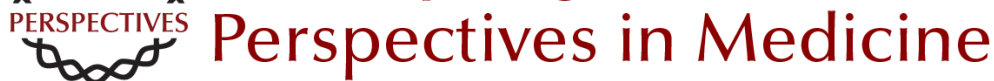

\section{Antifungal Pharmacokinetics and Pharmacodynamics}

Alexander J. Lepak and David R. Andes

Cold Spring Harb Perspect Med 2015; doi: 10.1101/cshperspect.a019653 originally published online November 10, 2014

\section{Subject Collection Human Fungal Pathogens}

\section{Evolutionary Perspectives on Human Fungal Pathogens John W. Taylor}

Black Molds and Melanized Yeasts Pathogenic to Humans Anuradha Chowdhary, John Perfect and G. Sybren de Hoog

Fungal Pathogens: Survival and Replication within Macrophages Andrew S. Gilbert, Robert T. Wheeler and Robin C. May

Innate Defense against Fungal Pathogens Rebecca A. Drummond, Sarah L. Gaffen, Amy G. Hise, et al.

Antifungal Pharmacokinetics and Pharmacodynamics Alexander J. Lepak and David R. Andes

Human Fungal Pathogens of Mucorales and Entomophthorales

Leonel Mendoza, Raquel Vilela, Kerstin Voelz, et al.

Functional Profiling of Human Fungal Pathogen Genomes

Alexi I. Goranov and Hiten D. Madhani

Aspergillus fumigatus and Related Species Janyce A. Sugui, Kyung J. Kwon-Chung, Praveen R. Juvvadi, et al.
Thermally Dimorphic Human Fungal Pathogens-Polyphyletic Pathogens with a Convergent

Pathogenicity Trait Anita Sil and Alex Andrianopoulos

Mechanisms of Antifungal Drug Resistance Leah E. Cowen, Dominique Sanglard, Susan J. Howard, et al.

Treatment Principles for Candida and Cryptococcus Laura C. Whitney and Tihana Bicanic

The Human Mycobiome Patrick C. Seed

Treatment Principles for the Management of Mold Infections

Dimitrios P. Kontoyiannis and Russell E. Lewis

Adaptive Immunity to Fungi Akash Verma, Marcel Wüthrich, George Deepe, et al.

The Candida Pathogenic Species Complex Siobhán A. Turner and Geraldine Butler

Fungal Morphogenesis Xiaorong Lin, J. Andrew Alspaugh, Haoping Liu, et al.

For additional articles in this collection, see http://perspectivesinmedicine.cshlp.org/cgi/collection/ 